\title{
In Vitro and In Vivo Short-Term Pulmonary Toxicity of Differently Sized Colloidal Amorphous $\mathrm{SiO}_{2}$
}

\author{
Martin Wiemann ${ }^{1, *}$, Ursula G. Sauer ${ }^{2}$, Antje Vennemann ${ }^{1}$, Sandra Bäcker ${ }^{3}$, \\ Johannes-Georg Keller ${ }^{4}$, Lan Ma-Hock ${ }^{5}$, Wendel Wohlleben ${ }^{4}$ and Robert Landsiedel ${ }^{5}$ \\ 1 IBR R\&D gGmbH Institute for Lung Health, Mendelstr. 11, 48149 Münster, Germany; \\ vennemann@ibe-ms.de \\ 2 Scientific Consultancy_Animal Welfare, 85579 Neubiberg, Germany; ursula.sauer@sauerug.de \\ 3 BASF SE, Human Biomonitoring and Industrial Hygiene, 67056 Ludwigshafen, Germany; \\ sandra.baecker@basf.com \\ 4 BASF SE, Advanced Materials Research, 67056 Ludwigshafen, Germany; \\ johannes-georg.keller@basf.com (J.-G.K.); wendel.wohlleben@basf.com (W.W.) \\ 5 BASF SE, Experimental Toxicology and Ecology, 67056 Ludwigshafen, Germany; \\ lan.ma-hock@basf.com (L.M.-H.); robert.landsiedel@basf.com (R.L.) \\ * Correspondence: martin.wiemann@ibe-ms.de
}

Received: 22 February 2018; Accepted: 9 March 2018; Published: 13 March 2018

\begin{abstract}
In vitro prediction of inflammatory lung effects of well-dispersed nanomaterials is challenging. Here, the in vitro effects of four colloidal amorphous $\mathrm{SiO}_{2}$ nanomaterials that differed only by their primary particle size $(9,15,30$, and $55 \mathrm{~nm})$ were analyzed using the rat NR8383 alveolar macrophage (AM) assay. Data were compared to effects of single doses of $15 \mathrm{~nm}$ and $55 \mathrm{~nm} \mathrm{SiO}_{2}$ intratracheally instilled in rat lungs. In vitro, all four elicited the release of concentration-dependent lactate dehydrogenase, $\beta$-glucuronidase, and tumor necrosis factor alpha, and the two smaller materials also released $\mathrm{H}_{2} \mathrm{O}_{2}$. All effects were size-dependent. Since the colloidal $\mathrm{SiO}_{2}$ remained well-dispersed in serum-free in vitro conditions, effective particle concentrations reaching the cells were estimated using different models. Evaluating the effective concentration-based in vitro effects using the Decision-making framework for the grouping and testing of nanomaterials, all four nanomaterials were assigned as "active." This assignment and the size dependency of effects were consistent with the outcomes of intratracheal instillation studies and available short-term rat inhalation data for $15 \mathrm{~nm} \mathrm{SiO} 2$. The study confirms the applicability of the NR8383 AM assay to assessing colloidal $\mathrm{SiO}_{2}$ but underlines the need to estimate and consider the effective concentration of such well-dispersed test materials.
\end{abstract}

Keywords: alveolar macrophage; short-term inhalation study (STIS); intratracheal instillation; in vitro cytotoxicity; 3R method; dosimetry; TNF $\alpha$; nanomaterial grouping; regulatory hazard assessment

\section{Introduction}

Engineered nanomaterials encompass a large variety of inorganic and organic chemicals. An abundance of nanoforms that differ, such as in primary particle size (PPS), shape, or surface function, can be produced for any given nanomaterial [1,2]. While an increasing number of scientific publications address safety assessments of engineered nanomaterials [3-7], it is widely acknowledged that toxicity testing to meet full regulatory information requirements, e.g., in accordance with Regulation (EC) No 1907/2006 on the Registration, Evaluation, Authorisation, and Restriction of Chemicals (REACH [8]), for every variant of a given nanomaterial would lead to an insurmountable amount of testing [9]. This would further stand in contradiction to the ethical and legal requirement to replace, reduce, and refine animal testing (3Rs principle) [10,11]. 
For many nanomaterials, inhalation is the predominant route of exposure [5,6,12]. A rat short-term inhalation study (STIS) is available that allows reducing and refining the use of animals as compared to the traditional Organisation for Economic Cooperation and Development (OECD) test guideline (TG) 412, Sub-acute inhalation toxicity: 28-day study [12-15]. By comparison, standardized in vitro assays to assess the cellular effects of nanomaterials continue to be unavailable [6,7,16-18]. Only a few of the numerous published in vitro studies investigating the cellular effects of nanomaterials were aimed at predicting in vivo toxicity potential [1,6,7,19-22].

Recently, a rat NR8383 alveolar macrophage (AM) assay has proven useful in predicting the short-term inhalation toxicity potential of nanomaterials and non-nanosized materials [22]. AMs serve as the first line of host defense against inhaled particles [23-26]. The NR8383 AM assay was founded on an assay originally developed for primary AMs by Rehn et al. [26-28]. In Wiemann et al. [22], the concept of the original assay was adapted to cultured rat NR8383 AMs that maintain their typical AM-like size and appearance, along with phagocytic and many immunological properties [29-31].

Due to its high predictivity of the short-term inhalation toxicity of nanomaterials, the NR8383 $\mathrm{AM}$ assay is the recommended in vitro assay in the Decision-making framework for the grouping and testing of nanomaterials (DF4nanoGrouping) [32,33]. The grouping of nanomaterials (or other substances) is widely recognized as a means to streamline regulatory testing needs [1,4,34-38], and the DF4nanoGrouping provides a comprehensive framework to assign nanomaterials to one of four main groups, termed MG1 to MG4, as explained in Box 1 [32,33].

Box 1. The DF4nanoGrouping [32,33].

In Tier 1 of the DF4nanoGrouping, three intrinsic material properties are evaluated, i.e., water solubility, particle morphology and chemical composition.

In Tier 2, three system-dependent properties are evaluated, i.e., dissolution in biological media, surface reactivity, and particle dispersibility, as well as in vitro cellular effects for which the NR8383 AM assay is the recommended test method.

Together, these grouping criteria allow identifying all nanomaterials as either (MG1) soluble, (MG2) biopersistent high aspect ratio, (MG3) passive, or (MG4) active nanomaterials.

If necessary, the outcome of the non-animal Tiers 1 and 2 is verified in Tier 3 using in vivo STIS data that also serve to sub-group the (MG4) active nanomaterials to specify the further testing needs.

Extensive case studies that also included different amorphous $\mathrm{SiO}_{2}$ nanomaterials confirmed the usefulness of the DF4nanoGrouping for hazard and risk assessment [33]. Amorphous $\mathrm{SiO}_{2}$ nanomaterials are widely used, e.g., in cement, paint, cosmetics, and food, and are produced using a variety of methods $[3,39,40]$. The outcome of the DF4nanoGrouping case studies highlighted the need to further investigate how different modifications of the same amorphous $\mathrm{SiO}_{2}$ can affect their intrinsic material properties, system-dependent properties, and toxicity potential [33].

Against this background, the present study aimed to evaluate the in vitro cellular effects and in vivo short-term pulmonary toxicity of colloidal amorphous $\mathrm{SiO}_{2}$ nanomaterials that differed only by PPS, and hence surface area: Levasil ${ }^{\circledR} 300 / 30 \%\left(9 \mathrm{~nm} \mathrm{SiO}_{2}\right)$, Levasil $^{\circledR}$ 200/40\% $\left(15 \mathrm{~nm} \mathrm{SiO}_{2}\right), \mathrm{Levasil}^{\circledR}$ 100/45\% (30 $\left.\mathrm{nm} \mathrm{SiO}_{2}\right)$, and Levasil ${ }^{\circledR}$ 50/50\% (55 $\mathrm{nm} \mathrm{SiO}_{2}$ ). These stable colloidal dispersions are synthesized by means of a growth process from an aqueous solution with dissociated molecular silicic acid [41]. Of note, whereas the Levasil ${ }^{\circledR}$ numberings relate to the respective materials' specific surface areas, the terms $9 \mathrm{~nm} \mathrm{SiO}_{2}, 15 \mathrm{~nm} \mathrm{SiO}_{2}$, etc., reflect their PPS. Larger Levasil ${ }^{\circledR}$ numberings (and thus surface areas) correspond to smaller PPSs.

By selecting four differently sized but otherwise identical test materials, the present study allowed for assessment of how the PPS of colloidal $\mathrm{SiO}_{2}$ affects its intrinsic material properties, system-dependent properties (dispersibility, dissolution rate, and surface reactivity, with a focus on behavior under cell culture conditions), and in vitro and in vivo pulmonary toxicity. Previous studies have attempted to correlate nanoparticle size or specific nanomaterial surface properties with toxic effects [40,42-51]. Specific correlations could not be shown consistently for different 
types of test materials with particle sizes of 1-100 $\mathrm{nm}$, the range used in regulatory nanomaterial definitions [52-54]. In the DF4nanoGrouping, particle size has been identified as a supplementary grouping criterion [32,33]. In vivo, the pulmonary toxicity of nanomaterials appears to be mainly explained by their chemical composition and/or surface reactivity $[5,55]$.

For in vitro assessment of $9 \mathrm{~nm} \mathrm{SiO} 2,15 \mathrm{~nm} \mathrm{SiO} 2,30 \mathrm{~nm} \mathrm{SiO}$, and $55 \mathrm{~nm} \mathrm{SiO}$, four cellular effects were measured in the NR8383 AM assay: extracellular release of (1) $\mathrm{H}_{2} \mathrm{O}_{2}$, reflecting the synthesis of reactive oxygen species (ROS); (2) lactate dehydrogenase (LDH), reflecting enzyme leakage from the cytosol; (3) $\beta$-glucuronidase (GLU), reflecting activation and/or membrane damage of the phagolysosomal compartment; and (4) biologically active tumor necrosis factor alpha (TNF $\alpha$ ) as a major proinflammatory cytokine [22]. In accordance with the NR8383 AM assay protocol [22], the cellular particle burden was estimated, because colloidal $\mathrm{SiO}_{2}$ nanomaterials show minimal gravitational settling [22]. Therefore, the in vitro test results obtained in the present study are expressed as nominal (total applied) concentration. In addition, the effective concentration, i.e., the proportion of nanoparticles in the homogeneous suspension that ended up in the bottom area of the cell culture vessel where the nanoparticles might reach the cells, was calculated [56-58].

For in vitro-in vivo comparison of test results, $15 \mathrm{~nm} \mathrm{SiO}_{2}$ and $55 \mathrm{~nm} \mathrm{SiO}{ }_{2}$ were further evaluated in an in vivo rat intratracheal instillation study [59]. Intratracheal instillation studies are considered useful in vivo screening tests, since the resulting lung burden is equal to the bolus dose of the test material. Finally, the outcomes of the NR8383 AM assay and the rat intratracheal instillation study were compared to published STIS data for $15 \mathrm{~nm} \mathrm{SiO}_{2}$ [15].

\section{Results}

\subsection{Test Materials and Test Material Characterization}

Table 1 provides an overview of the intrinsic material properties and system-dependent properties of $9 \mathrm{~nm} \mathrm{SiO}_{2}, 15 \mathrm{~nm} \mathrm{SiO}_{2}, 30 \mathrm{~nm} \mathrm{SiO}_{2}$, and $55 \mathrm{~nm} \mathrm{SiO}_{2}$. Compared to the manufacturer's specification of PPS, an increase in particle size of only $40-60 \%$ was observed when the test materials were suspended in protein-free F-12K medium (the main cell culture medium used in the present study), Krebs-Ringer phosphate glucose (KRPG) buffer (used to assess in vitro $\mathrm{H}_{2} \mathrm{O}_{2}$ synthesis and release), or $0.9 \% \mathrm{NaCl}$ solution (used to prepare the test materials in the intratracheal instillation study). The dispersed sizes of the respective test materials were nearly identical between these three protein-free media, indicating strong stabilization of all colloidal amorphous $\mathrm{SiO}_{2}$ by negative charge. Only in serum containing Dulbecco's Modified Eagle Medium (DMEM) supplemented with $10 \%$ fetal calf serum (FCS), which is not used in the NR8383 AM assay, were strong interaction and agglomeration recorded.

Water solubility of the test materials, determined by inductively coupled plasma-mass spectrometry (ICP-MS) after force filtration, as described in OECD [60], decreased with increasing PPS (from $48 \mathrm{mg} / \mathrm{L}$ for $9 \mathrm{~nm} \mathrm{SiO}{ }_{2}$ to $7 \mathrm{mg} / \mathrm{L}$ for $55 \mathrm{~nm} \mathrm{SiO}{ }_{2}$; Table 1). In flow-through testing of the dissolution rate of the test materials in phagolysosomal simulant fluid ( $\mathrm{pH} 4.5$ ), all four colloidal $\mathrm{SiO}_{2}$ exhibited minimal dissolution. Interestingly, the concentration of ionic species increased nonlinearly with increasing surface area, suggesting a transformation of the particulate species, such as by gel formation [61].

All four test materials exhibited a similar strongly negative charge (Table 1): $9 \mathrm{~nm} \mathrm{SiO} 2:-43 \mathrm{mV}$; $15 \mathrm{~nm} \mathrm{SiO} 2:-48 \mathrm{mV} ; 30 \mathrm{~nm} \mathrm{SiO}{ }_{2}:-55 \mathrm{mV}$; and $55 \mathrm{~nm}-\mathrm{SiO}_{2}:-50 \mathrm{mV}$. It was not possible to discern a clear trend that charge was affected by particle size.

For $9 \mathrm{~nm}, 15 \mathrm{~nm}$, and $30 \mathrm{~nm} \mathrm{SiO}$, very similar surface chemistry was recorded (determined by x-ray photoelectron spectroscopy [62]). Their specific surface reactivity (assessed by surface-induced biological oxidative damage and expressed as $\mathrm{nM}$ Trulox equivalent units per $\mathrm{m}^{2}$ nanomaterial [62]) was also identical within error. By contrast, the $55 \mathrm{~nm} \mathrm{SiO}$ had a significantly different surface chemistry and, accordingly, also showed significantly different specific surface reactivity (half the reactivity of the other materials, but still significant above background) (Table 1). 
Table 1. Characterization of colloidal amorphous $\mathrm{SiO}_{2}$ nanomaterials (adapted from Maser et al. [59] and Arts et al. [33]).

\begin{tabular}{|c|c|c|c|c|c|}
\hline Parameter (Test Method) & Unit & $9 \mathrm{~nm} \mathrm{\textrm {SiO } _ { 2 }}$ & $15 \mathrm{~nm} \mathrm{SiO}_{2} \mathrm{~g}$ & $30 \mathrm{~nm} \mathrm{SiO}{ }_{2}$ & $55 \mathrm{~nm} \mathrm{SiO}{ }_{2}$ \\
\hline Specific surface area (specified by producer) & $\mathrm{m}^{2} / \mathrm{g}$ & 300 & 200 & 100 & 50 \\
\hline Solid concentration & $\%$ & 30 & 40 & 45 & 50 \\
\hline Purity/crystalline phase (XRD) ${ }^{a}$ & $\% /$ qualitative & not determined & $>99 \% /$ amorphous & not determined & $>99 \%$ /amorphous \\
\hline Appearance & qualitative & opalescent & opalescent & milky & milky \\
\hline $\mathrm{pH}$ value (specified by producer) & - & 10 & 10 & 10 & 10 \\
\hline Primary particle size (specified by producer) & $\mathrm{nm}$ & 9 & 15 & 30 & 55 \\
\hline Particle size \pm SD in water (intensity-averaged, DLS) ${ }^{b}$ & $\mathrm{~nm}$ & $26 \pm 0.7$ & $48 \pm 0.4$ & $85 \pm 0.6$ & $117 \pm 0.4$ \\
\hline Particle size in KRPG medium (AUC) & $\mathrm{nm}$ & 13 & 24 & 41 & 82 \\
\hline Particle size in F-12K medium (AUC) ${ }^{\mathrm{c}}$ & $\mathrm{nm}$ & 13 & 21 & 47 & 87 \\
\hline Particle size in $0.9 \% \mathrm{NaCl}(\mathrm{AUC})^{\mathrm{c}}$ & $\mathrm{nm}$ & not determined & 26 & not determined & 77 \\
\hline Particle size in DMEM + 10\% FCS (AUC) & $\mathrm{D}_{50}(\mathrm{~nm})$ & not determined & 289 & not determined & 384 \\
\hline Water solubility $(\mathrm{pH} 7 \text {, static, filtration } 5 \mathrm{kDa})^{\mathrm{d}}$ & $\mathrm{mg} / \mathrm{L}$ & 48 & 43 & 19 & 7 \\
\hline $\begin{array}{l}\text { Dissolution rate in lysosomal medium (pH 4.5 PSF, } \\
\text { flow-through } 5 \mathrm{kDa} \text { ) }\end{array}$ & $\mathrm{ng} / \mathrm{cm}^{2} / \mathrm{h}$ & 0.034 & 0.044 & 0.066 & 0.088 \\
\hline Zeta potential \pm SD (Zetasizer) & $\mathrm{mV}$ & -43 & -48 & -55 & -50 \\
\hline Surface chemistry (XPS) ${ }^{a}$ & atomic \% & O 69 | Si 28 | C 2 | Na 1 & $\mathrm{O} 65|\mathrm{Si} 29| \mathrm{C} 4|\mathrm{Na} 1| \mathrm{N} 0.6$ & $\mathrm{O} 68 \mid \mathrm{Si} 29$ | C 2 | Na 1 & $\begin{array}{c}\mathrm{O} 53 \text { | Si } 40 \text { | C } 5 \text { | Na } 2 \\
\text { | N } 0.3 \text { | Cl } 0.5 \\
\end{array}$ \\
\hline Surface organic contaminations (SIMS) ${ }^{a}$ & qualitative & not determined & $\begin{array}{c}\mathrm{SiO}_{2} \text { cluster; organics, traces of } \\
\text { surfactant }\end{array}$ & not determined & $\begin{array}{l}\mathrm{SiO}_{2} \text { cluster; less organics } \\
\text { than } 15 \mathrm{~nm} \mathrm{SiO} \\
\end{array}$ \\
\hline Specific surface reactivity $\pm \mathrm{SD}\left(\mathrm{sBOD}\right.$ at $\left.1 \mathrm{~m}^{2} / \mathrm{mL}\right)$ & $\begin{array}{l}\mathrm{nM} \mathrm{TEU} / \mathrm{m}^{2} \\
\text { nanomaterial }\end{array}$ & $13.9 \pm 0.3$ nonoxidative & $14 \pm 0.5$ nonoxidative & $13.2 \pm 0.0$ nonoxidative & $7.5 \pm 0.2$ nonoxidative \\
\hline Surface reactivity $(\mathrm{ESR}+\mathrm{CPH})^{\mathrm{e}, \mathrm{f}}$ & relative to $\mathrm{D}_{2} \mathrm{O}$ & not determined & $4 / \mathrm{p}$-f s: 0.88 & not determined & not determined \\
\hline Surface ROS generation (ESR + DMPO) ${ }^{e, f}$ & relative to $\mathrm{D}_{2} \mathrm{O}$ & not determined & $11 / p$-f s: 6.3 & not determined & not determined \\
\hline
\end{tabular}

Abbreviations: AAN: average agglomeration number; AUC: analytical ultracentrifugation; DLS: dynamic light scattering. DMEM: Dulbecco's Modified Eagle Medium; ESR + CPH: electron spin resonance making use of centrophenoxine spin traps; ESR + DMPO: electron spin resonance making use of dimethy-pyrroline-N-oxide spin traps; FCS: fetal calf serum; KRPG: Krebs-Ringer phosphate glucose; $p$-f s: particle-free supernatant; PSF: phagolysosomal simulant fluid; ROS: reactive oxygen species; sBOD: surface-induced biological oxidative damage; SD: standard deviation; SIMS: secondary ion mass spectrometry; TEU: Trulox equivalent unit; XPS: x-ray photoelectron spectroscopy; XRD: $x$-ray diffusion. ${ }^{\text {a: }}$ Published by

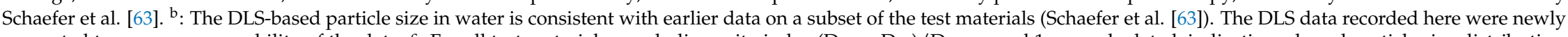
generated to ensure comparability of the data. ${ }^{c}$ : For all test materials, a polydispersity index $\left(D_{90}-D_{10}\right) / D_{50}$ around 1 was calculated, indicating a broad particle size distribution. $\mathrm{d}$ : Hypothetically, the soluble content might be a mix of ions, cluster, and smallest particles. Since the $5 \mathrm{kDa}$ filter cutoff corresponds to pore sizes below $1 \mathrm{~nm}$, all compounds able to pass the filter are not nanomaterials. ${ }^{e}$ : Published by Izak-Nau and Voetz [64]. ${ }^{\mathrm{f}}$ : Surface reactivity and $\mathrm{ROS}$ formation were determined relative to the reference material deuterium oxide $\left(\mathrm{D}_{2} \mathrm{O}\right.$; ${ }^{2} \mathrm{H}_{2} \mathrm{O}$ ). Assuming $30 \%$ variability of the methodology, only measurements $>1.3$ are considered relevant, taking into account that this value serves as a guiding principle, not an absolute value. g: Applying Langmuir isotherm approximation, Chen et al. [65] assessed the following infinite dilution adsorption descriptors for $15 \mathrm{~nm} \mathrm{SiO} 2$ : $\mathrm{r}$ : 0.61 ; $\mathrm{p}$ : -0.32 ; a: 1.16 ; b: -1.79 ; value. $\mathrm{g}$ : Applying Langmuir isotherm approximation, Chen et al. [65] assessed the following infinite dilution adsorption descriptors for $15 \mathrm{~nm} \mathrm{SiO}_{2}: \mathrm{r}: 0.61 ; \mathrm{p}:-0.32$; a: 1.16 ; $\mathrm{b}:-1.79$;
$\mathrm{v}$ : 1.15 . The parameters $\mathrm{r}, \mathrm{p}, \mathrm{a}, \mathrm{b}$, and $\mathrm{v}$ represent the five major molecular interaction forces in the nanoparticle adsorption processes, i.e., the five descriptors of the biological surface adsorption index: lon-pair electrons, polarity/polarizability, hydrogen-bond donor, hydrogen-bond acceptor, and London dispersion, respectively. 


\subsection{Dose Setting and In Vitro Effective Concentration}

The test material dose applied in the rat intratracheal instillation study (bolus dose of $360 \mu \mathrm{g} / \mathrm{lung}$ ) was set to reflect the rat lung burden of $342 \mu \mathrm{g}$ immediately after 6-day exposure to an aerosol concentration of $50 \mathrm{mg} / \mathrm{m}^{3}$ in the STIS [15]. (Of note, Maser et al. [59] presented ex vivo genotoxicity studies performed with lung and bone marrow cells from the rats submitted to the intratracheal instillation study described here and inadvertently reported that 5-day exposure to only $10 \mathrm{mg} / \mathrm{m}^{3}$ $15 \mathrm{~nm} \mathrm{SiO} 2$ in the rat STIS yielded a lung burden of $342 \mu \mathrm{g}$.)

The test material concentration applied in the NR8383 AM assay ranged from 5.6 to $45 \mu \mathrm{g} / \mathrm{mL}$, as pilot studies showed that this fully covered the whole range of effects (data not shown). Nominally, the highest concentration of $45 \mu \mathrm{g} / \mathrm{mL}$ could lead to a mean cell burden of $27 \mathrm{pg} / \mathrm{cell}$ (cf. Section 4.2 for calculation). For overall evaluation of the in vitro data, the particle mass-based concentrations $(\mu \mathrm{g} / \mathrm{mL})$ were multiplied with the respective test material's surface area $\left(\mathrm{m}^{2} / \mathrm{g}\right.$, assessed by the Brunauer, Teller, and Emmett (BET) method), converting them to particle surface area-based concentrations $\left(\mathrm{mm}^{2} / \mathrm{mL}^{2}\right.$ (Table 2).

To estimate the effective concentration under cell culture conditions (affected by both particle gravitational settling and diffusion), the in vitro sedimentation, diffusion, and dosimetry (ISDD) model [66] was used. This was supplemented by data from analytical ultracentrifugation (AUC) dosimetry tests that allow measuring particle gravitational settling. The term effective concentration describes the particle mass per volume or particle surface area per volume-based dose $(\mu \mathrm{g} / \mathrm{mL}$ and $\mathrm{mm}^{2} / \mathrm{mL}$ ). Nevertheless, it is the proportion of the nominal dose (applied as homogeneous suspension) that reaches the bottom area of the wells and thus may have access to the cells that is relevant for the elicitation of cellular effects. The ISDD-based effective concentrations ranged from $15.8 \%$ for $55 \mathrm{~nm}$ $\mathrm{SiO}_{2}$ to $31.0 \%$ for $9 \mathrm{~nm} \mathrm{SiO}_{2}$ (Table 2).

In the AUC dosimetry tests, the proportion of test materials (suspended in KRPG butter) that accumulated at the bottom of the vials within $24 \mathrm{~h}$ ranged from $4.3 \%$ for $55 \mathrm{~nm} \mathrm{SiO}$ to $0.4 \%$ for $9 \mathrm{~nm}$ $\mathrm{SiO}_{2}$ (cf. Supplementary Information (SI), Table S1 and Figure S1). Values for colloidal $\mathrm{SiO}_{2}$ in other protein-free media are expected to lie in the same order of magnitude, since the particle sizes of the test materials were nearly identical in all protein-free media (Table 1). The AUC tests suggested that particle gravitational sedimentation to the bottom of the wells during the $16 \mathrm{~h}$ incubation period in the NR8383 AM assay was negligible. Hence, the effective concentrations of colloidal $\mathrm{SiO}_{2}$ appear to be dominated by diffusion.

Importantly, the ISDD model [66], which addresses both particle sedimentation and diffusion, assumes a "perfectly adsorptive (sticky) lower boundary condition" [67], i.e., a probability of 1 that particles that come close to the cells adhere to them. Taking into account the pronounced negative charge of colloidal $\mathrm{SiO}_{2}$ (Table 1), particles might also diffuse to and from the bottom of the wells and the cells, so the probability of particle adherence might be much lower than 1 . However, to the best of the authors' knowledge, there is no test method that allows quantitative measurement of the fraction of colloidal $\mathrm{SiO}_{2}$ used in the present study that adhere to cultured cells. Therefore, the results presented below use ISDD-based effective concentrations even though the true availability of colloidal $\mathrm{SiO}_{2}$ is likely to be lower (cf. Section 3.1 for further discussion). 
Table 2. Particle mass-based test material concentrations juxtaposed with corresponding nominal and effective surface area-based concentrations of the test materials.

\begin{tabular}{|c|c|c|c|c|c|c|c|c|c|c|}
\hline \multirow{4}{*}{ Test Material } & \multirow{3}{*}{$\begin{array}{l}\text { Surface Area } \\
\text { (BET Method) }\end{array}$} & \multirow{3}{*}{$\begin{array}{c}\text { Effective } \\
\text { Concentration } \\
\text { (ISDD Model) }^{b}\end{array}$} & \multicolumn{8}{|c|}{ Surface Area-Based Test Material Concentrations ${ }^{\text {a }}$} \\
\hline & & & \multicolumn{2}{|c|}{$5.6 \mu \mathrm{g} / \mathrm{mL}$ Corresponds to: } & \multicolumn{2}{|c|}{$11.2 \mu \mathrm{g} / \mathrm{mL}$ Corresponds to: } & \multicolumn{2}{|c|}{$22.5 \mu \mathrm{g} / \mathrm{mL}$ Corresponds to: } & \multicolumn{2}{|c|}{$45.0 \mu \mathrm{g} / \mathrm{mL}$ Corresponds to: } \\
\hline & & & Nominal & Effective & Nominal & Effective & Nominal & Effective & Nominal & Effective \\
\hline & $\mathrm{m}^{2} / \mathrm{g}$ & $\frac{\%}{\%}$ & $\begin{array}{c}\text { Concentration } \\
\mathrm{mm}^{2} / \mathrm{mL}\end{array}$ & $\begin{array}{l}\text { Concentration } \\
\mathrm{mm}^{2} / \mathrm{mL}\end{array}$ & $\begin{array}{c}\text { Concentration } \\
\mathrm{mm}^{2} / \mathrm{mL}\end{array}$ & $\begin{array}{l}\text { Concentration } \\
\mathrm{mm}^{2} / \mathrm{mL}\end{array}$ & $\begin{array}{c}\text { Concentration } \\
\mathrm{mm}^{2} / \mathrm{mL}\end{array}$ & $\begin{array}{l}\text { Concentration } \\
\mathrm{mm}^{2} / \mathrm{mL}\end{array}$ & $\begin{array}{c}\text { Concentration } \\
\mathrm{mm}^{2} / \mathrm{mL}\end{array}$ & $\begin{array}{l}\text { Concentration } \\
\mathrm{mm}^{2} / \mathrm{mL}\end{array}$ \\
\hline $55 \mathrm{~nm} \mathrm{SiO}_{2}$ & 50 & 15.8 & 280 & 44 & 560 & 88 & 1125 & 178 & 2250 & 356 \\
\hline $30 \mathrm{~nm} \mathrm{SiO} 2$ & 100 & 17.4 & 560 & 97 & 1120 & 195 & 2250 & 392 & 4500 & 783 \\
\hline $15 \mathrm{~nm} \mathrm{SiO} 2$ & 200 & 24.6 & 1120 & 276 & 2240 & 551 & 4500 & 1107 & 9000 & 2214 \\
\hline $9 \mathrm{~nm} \mathrm{SiO} 2$ & 300 & 31.0 & 1680 & 521 & 3360 & 1042 & 6750 & 2093 & 13,500 & 4185 \\
\hline
\end{tabular}

Abbreviations: BET: Brunauer, Teller, and Emmett; ISDD: in vitro sedimentation, diffusion, and dosimetry. ${ }^{a}$ : To convert the nominal particle mass-based test material concentrations

$(\mu \mathrm{g} / \mathrm{mL})$ into particle surface area-based concentrations $\left(\mathrm{mm}^{2} / \mathrm{mL}\right)$, they were multiplied with the respective test material's surface area $\left(\mathrm{m}^{2} / \mathrm{g}\right)$ as assessed by the BET method [22].

$\mathrm{b}$ : The effective concentration of the test materials in F-12K medium after $16 \mathrm{~h}$ incubation was determined using the ISDD model [66]. For the modelling, the following parameters were set: dish depth: $0.006 \mathrm{~m}$; volume: $0.2 \mathrm{~mL}$; viscosity $\left(\mathrm{H}_{2} \mathrm{O}, 37^{\circ} \mathrm{C}\right): 0.00074 \mathrm{mPa}$ s s; temperature: $310 \mathrm{~K} ; \mathrm{SiO}_{2}$ density: $2.3 \mathrm{~g} / \mathrm{mL}$; particle size in F-12K medium $(c f$. Table 1$)$ equals agglomerate size; incubation time: $16 \mathrm{~h}$; packing factor: 0.64; fractal dimension: 42,796.00. 


\subsection{In Vitro NR8383 AM Assay}

\subsection{1. $\mathrm{H}_{2} \mathrm{O}_{2}$ Synthesis}

In the Amplex $\operatorname{Red}^{\circledR}$ assay, 90 min incubation with 5.6-45 $\mu \mathrm{g} / \mathrm{mL} 55 \mathrm{~nm} \mathrm{SiO}$ or $30 \mathrm{~nm} \mathrm{SiO}_{2}$ did not result in significant $\mathrm{H}_{2} \mathrm{O}_{2}$ synthesis. For the smaller 9 and $15 \mathrm{~nm} \mathrm{SiO}$, moderately significant responses were observed at the highest concentration $(45 \mu \mathrm{g} / \mathrm{mL} ; p$-values $\leq 0.01$ and $\leq 0.05$, respectively) (Figure 1 and SI; Table S2).

\subsubsection{LDH and GLU Release}

For all four test materials, LDH release increased with increasing concentration (Figure 1 and SI; Table S2; $c f$. SI, Table S3 for test results expressed as $\mathrm{x}$-fold change compared to corresponding vehicle controls). At the highest nominal concentration $(45 \mu \mathrm{g} / \mathrm{mL})$, all test materials elicited highly significant LDH release ( $p$-value $\leq 0.001$ ). Additionally, $9 \mathrm{~nm}$ and $15 \mathrm{~nm} \mathrm{SiO} 2$ elicited moderately significant effects at $22.5 \mu \mathrm{g} / \mathrm{mL}$ ( $p$-values $\leq 0.05$ and $\leq 0.01$, respectively). Hence, the two smaller test materials induced significant LDH release at lower concentrations than the two larger test materials. GLU release upon treatment with the four test materials largely reflected LDH release (Figure 1 and Table S2). However, it was less pronounced and the maximum values did not exceed 16\% of GLU release elicited by the positive control $0.1 \%$ Triton $X$ (Table S2).

(a)

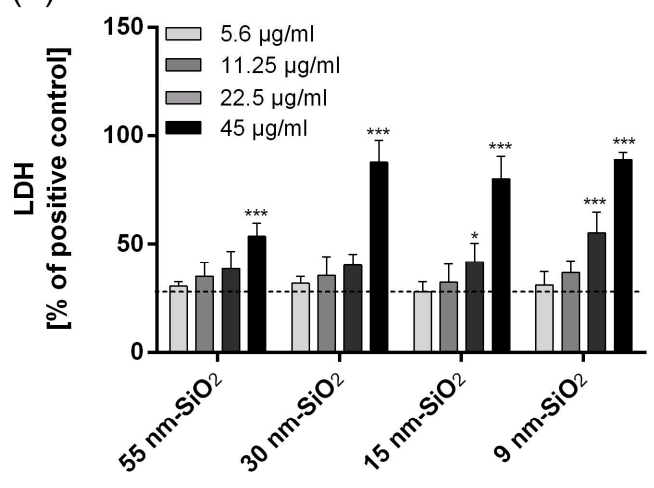

(c)

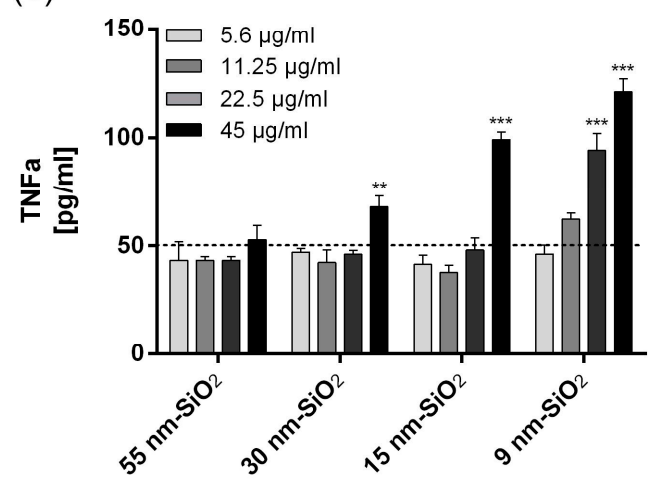

(b)

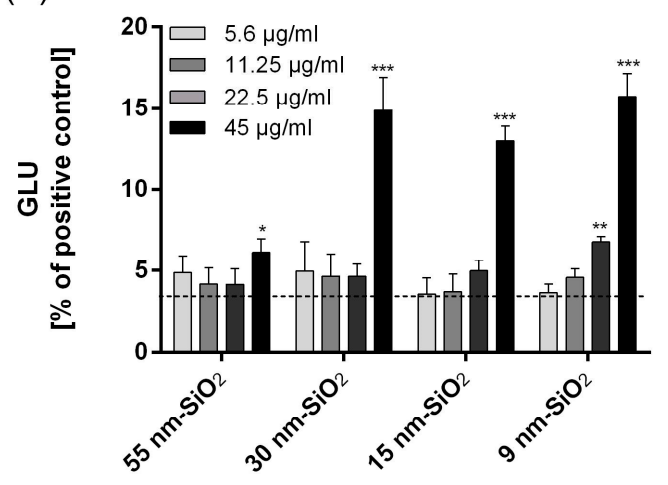

(d)

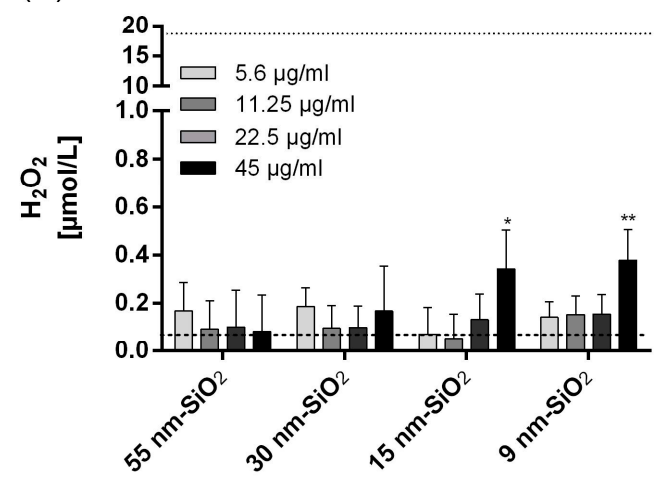

Figure 1. In vitro effects induced by $9 \mathrm{~nm} \mathrm{SiO}, 15 \mathrm{~nm} \mathrm{SiO}_{2}, 30 \mathrm{~nm} \mathrm{SiO}$, and $55 \mathrm{~nm} \mathrm{SiO}_{2}$ in the NR8383 alveolar macrophage (AM) assay. Cell culture supernatants were assessed for (a) lactate dehydrogenase ( $\mathrm{LDH}$, expressed relative to the positive control, $0.1 \%$ Triton $\mathrm{X}-100)$; (b) $\beta$-glucuronidase (GLU, expressed relative to the positive control); (c) tumor necrosis factor alpha (TNF $\alpha$ ); and (d) $\mathrm{H}_{2} \mathrm{O}_{2}$. Values are expressed as means of three independent test runs \pm standard deviation ${ }^{*} p$-value $\leq 0.05$; ** $p$-value $\leq 0.01 ; * * *$-value $\leq 0.001)$. Levels of untreated vehicle control are indicated by dashed lines. For $\mathrm{H}_{2} \mathrm{O}_{2}$ measurement, the level reached upon application of $180 \mu \mathrm{g} / \mathrm{mL}$ zymosan (positive control) is indicated as a dotted line. 
As determined by TNF $\alpha$-specific enzyme-linked immunosorbent assay (ELISA), TNF $\alpha$ content in the supernatant of the treated NR8383 AMs generally increased with increasing test material concentration. Further, at equal nominal concentrations of 22.5 and $45 \mu \mathrm{g} / \mathrm{mL}$, TNF $\alpha$ release increased with decreasing particle size of the test materials. The $55 \mathrm{~nm} \mathrm{SiO} 2$ did not elicit significant TNF $\alpha$ release at any concentration $(5.6-45 \mu \mathrm{g} / \mathrm{mL}) ; 30 \mathrm{~nm} \mathrm{SiO}, 15 \mathrm{~nm} \mathrm{SiO}$, and $9 \mathrm{~nm} \mathrm{SiO} 2$ induced significant $\mathrm{TNF} \propto$ release at $45 \mu \mathrm{g} / \mathrm{mL}$ ( $p$-values $\leq 0.01, \leq 0.001$, and $\leq 0.001$, respectively). Furthermore, the $9 \mathrm{~nm}$ $\mathrm{SiO}_{2}$ induced significant TNF $\alpha$ release at $22.5 \mu \mathrm{g} / \mathrm{mL}$ ( $p$-value $\leq 0.001$ ) (Figure 1 and Table S2).

Plotting the TNF $\alpha$ release data for all four test materials as surface area-based concentrations yielded sigmoidal curves (Figure $2 \mathrm{a}, \mathrm{b}$ ), with $\mathrm{R}^{2}$ values of 0.93 (ISDD-calculated effective concentrations) and 0.94 (nominal concentrations). $\mathrm{EC}_{50}$ values were $4873 \mathrm{~mm}^{2} / \mathrm{mL}$ and $6702 \mathrm{~mm}^{2} / \mathrm{mL}$, respectively (Figure 2a,b). When the data were plotted as particle mass-based nominal concentrations, no such regularity was observed (Figure 2c). These plots indicate that effects were surface area-dependent (and hence also size-dependent).

(a)

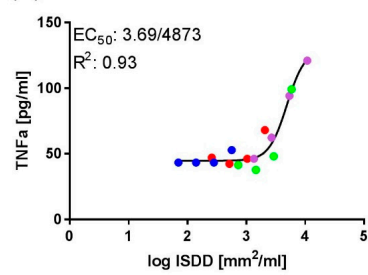

(b)

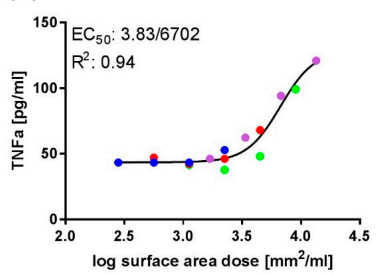

(c)

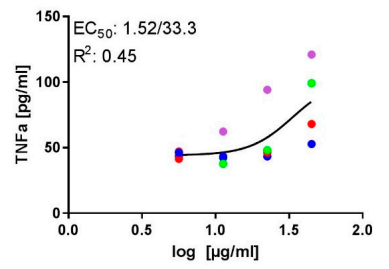

Figure 2. Combined evaluation of TNF $\alpha$ release induced by $9 \mathrm{~nm} \mathrm{SiO}_{2}, 15 \mathrm{~nm} \mathrm{SiO} 2,30 \mathrm{~nm} \mathrm{SiO}$, and $55 \mathrm{~nm} \mathrm{SiO} 2$ in the NR8383 AM assay. Purple dots: $9 \mathrm{~nm} \mathrm{SiO}$; green: $15 \mathrm{~nm} \mathrm{SiO}{ }_{2}$; red: $30 \mathrm{~nm}$ $\mathrm{SiO}_{2}$; blue: $55 \mathrm{~nm} \mathrm{SiO}_{2}$. TNF $\alpha$ release was plotted by (a) particle surface area-based effective concentration (calculated by ISDD model), (b) particle surface area-based nominal concentration, and (c) nominal particle mass-based concentration $(\mu \mathrm{g} / \mathrm{mL})$. Plots were created with GraphPad Prism 7 applying the Levenberg-Marquardt method for nonlinear regression. EC 50 values (test material concentrations inducing $50 \%$ increase in TNF $\alpha$ release as compared to vehicle control) are expressed as logarithmic/nonlogarithmic values (with the same units as the respective $x$ axes).

\subsubsection{Overall Evaluation of In Vitro Test Results to Distinguish between Passive and Active Test Materials}

Table 3 provides an overview of the in vitro lowest observed adverse effect concentrations (LOAECs, defined as the lowest test material concentration eliciting a significant cellular effect) recorded for $9 \mathrm{~nm} \mathrm{SiO}_{2}, 15 \mathrm{~nm} \mathrm{SiO}_{2}, 30 \mathrm{~nm} \mathrm{SiO}_{2}$, and $55 \mathrm{~nm} \mathrm{SiO}_{2}$ in the NR8383 AM assay. For each test material, the parameters $\left(\mathrm{H}_{2} \mathrm{O}_{2}, \mathrm{LDH}, \mathrm{GLU}\right.$, or TNF $\alpha$ release) for which the in vitro LOAEC undercut the previously set threshold of $6000 \mathrm{~mm}^{2} / \mathrm{mL}$ [22] were recorded as positive. Test materials were assessed as active (MG4) if at least two parameters were positive, and passive (MG3) if no or only one parameter was positive ( $c f$. Section 4.3.4 for further details on this two-out-of-four prediction model and on the setting of the $6000 \mathrm{~mm}^{2} / \mathrm{mL}$ threshold).

Applying the two-out-of-four prediction model to the effective concentration-based in vitro LOAECs, all four colloidal $\mathrm{SiO}_{2}$ were assessed as active (MG4): for $55 \mathrm{~nm} \mathrm{SiO}$, the in vitro LOAECs recorded for LDH and GLU release undercut the $6000 \mathrm{~mm}^{2} / \mathrm{mL}$ threshold (two parameters positive); for $30 \mathrm{~nm} \mathrm{SiO}$, the in vitro LOAEC recorded for TNF $\alpha$ release (three parameters positive); and for $9 \mathrm{~nm} \mathrm{SiO}{ }_{2}$ and $15 \mathrm{~nm} \mathrm{SiO}$, all four in vitro LOAECs undercut the $6000 \mathrm{~mm}^{2} / \mathrm{mL}$ threshold (four parameters positive) (Table 3 ).

In contrast, applying the two-out-of-four prediction model to the nominal concentration-based in vitro LOAECs, the same overall outcome was obtained for only $30 \mathrm{~nm} \mathrm{SiO}_{2}$ and $55 \mathrm{~nm} \mathrm{SiO}_{2}$ (indicating activity (MG4)), whereas $9 \mathrm{~nm} \mathrm{SiO} 2$ and $15 \mathrm{~nm} \mathrm{SiO}$ were assessed as passive (MG3) (15 nm $\mathrm{SiO}_{2}$ : only $\mathrm{LDH}$ positive; $9 \mathrm{~nm} \mathrm{SiO}_{2}$ : all four parameters negative) (Table 3). 
Table 3. Effects elicited by $55 \mathrm{~nm} \mathrm{SiO}_{2}, 30 \mathrm{~nm} \mathrm{SiO}_{2}, 15 \mathrm{~nm} \mathrm{SiO}_{2}$, and $9 \mathrm{~nm} \mathrm{SiO}_{2}$ in the $\mathrm{NR}_{3} 383 \mathrm{AM}$ assay: overall evaluation.

\begin{tabular}{|c|c|c|c|c|c|c|c|c|c|c|c|c|c|c|c|}
\hline \multirow{3}{*}{ Test Material } & \multirow{3}{*}{$\begin{array}{l}\text { Surface Area }\left(\mathrm{m}^{2} / \mathrm{g} \text {; }\right. \\
\text { BET Method) }\end{array}$} & \multicolumn{4}{|c|}{ In Vitro LOAEC $(\mu \mathrm{g} / \mathrm{mL})^{a}$} & \multicolumn{8}{|c|}{ In Vitro LOAEC $\left(\mathrm{mm}^{2} / \mathrm{mL}\right)^{a}$} & \multirow{2}{*}{\multicolumn{2}{|c|}{$\begin{array}{c}\text { Number of Positive } \\
\text { Parameters }\end{array}$}} \\
\hline & & $\mathrm{H}_{2} \mathrm{O}_{2}$ & LDH & GLU & TNF $\alpha$ & \multicolumn{2}{|c|}{$\mathrm{H}_{2} \mathrm{O}_{2}$} & \multicolumn{2}{|c|}{ LDH } & \multicolumn{2}{|c|}{ GLU } & \multicolumn{2}{|c|}{ TNF $\alpha$} & & \\
\hline & & \multicolumn{4}{|c|}{ Nominal Concentration } & $\begin{array}{l}\text { Nom. } \\
\text { Conc. }\end{array}$ & $\begin{array}{l}\text { Eff. } \\
\text { Conc. }\end{array}$ & $\begin{array}{l}\text { Nom. } \\
\text { Conc. }\end{array}$ & $\begin{array}{l}\text { Eff. } \\
\text { Conc. }\end{array}$ & $\begin{array}{l}\text { Nom. } \\
\text { Conc. }\end{array}$ & $\begin{array}{l}\text { Eff. } \\
\text { Conc. }\end{array}$ & $\begin{array}{l}\text { Nom. } \\
\text { Conc. }\end{array}$ & $\begin{array}{l}\text { Eff. } \\
\text { Conc. }\end{array}$ & $\begin{array}{l}\text { Nom. } \\
\text { Conc. }\end{array}$ & Eff. Conc. \\
\hline $55 \mathrm{~nm} \mathrm{SiO}_{2}$ & 50 & n.s. & 45 & 45 & n.s. & n.s. & n.s. & 2250 & 356 & 2250 & 356 & n.s. & n.s. & 2 & 2 \\
\hline $30 \mathrm{~nm} \mathrm{SiO}{ }_{2}$ & 100 & n.s. & 45 & 45 & 45 & n.s. & n.s. & 4500 & 783 & 4500 & 783 & 4500 & 783 & 3 & 3 \\
\hline $15 \mathrm{~nm} \mathrm{SiO}$ & 200 & 45 & 22.5 & 45 & 45 & 9000 & 2214 & 4500 & 1107 & 9000 & 2214 & 9000 & 2214 & 1 & 4 \\
\hline $9 \mathrm{~nm} \mathrm{SiO} 2$ & 300 & 45 & 22.5 & 22.5 & 22.5 & 13,500 & 4185 & 6750 & 2093 & 6750 & 2093 & 6750 & 2093 & 0 & 4 \\
\hline $15 \mathrm{~nm} \mathrm{SiO}_{2}{ }^{\mathrm{b}}$ & 200 & 45 & 22.5 & 45 & 22.5 & \multicolumn{2}{|c|}{9000} & \multicolumn{2}{|c|}{4500} & \multicolumn{2}{|c|}{9000} & \multicolumn{2}{|c|}{4500} & \multicolumn{2}{|r|}{2} \\
\hline
\end{tabular}

9000

9000

dehydrogenase; LOAEC: lowest observed adverse effect concentration; MG: main group; n.s.: not significant; Nom. Conc.: nominal concentration; TNF $\alpha$ : tumor necrosis factor alpha. : For all four parameters $\left(\mathrm{H}_{2} \mathrm{O}_{2}, \mathrm{LDH}, \mathrm{GLU}\right.$, and TNF $\alpha$ release), the in vitro LOAECs (i.e., the lowest concentrations that elicited significant effects; $c f$. Table S2) are shown as nominal concentrations (expressed as mass/volume $(\mu \mathrm{g} / \mathrm{mL})$ and surface area/volume $\left.\left(\mathrm{mm}^{2} / \mathrm{mL}\right)\right)$ and as effective concentrations (expressed as surface area/volume $\left.\left(\mathrm{mm}{ }^{2} / \mathrm{mL}\right)\right)(c f$. Table 2$)$. Surface area/volume-based in vitro LOAECs that undercut the threshold of $6000 \mathrm{~mm}^{2} / \mathrm{mL}$ were assessed as positive (highlighted with gray shading). The number of positive parameters of the four parameters were positive (gray shading in the far-right column). ${ }^{\text {b }}$ : Published by Wiemann et al. [22]. 


\subsubsection{In Vivo Rat Intratracheal Instillation Study}

Before and after instillation, rats treated with single bolus doses of $360 \mu \mathrm{gg} 15 \mathrm{~nm}$ or $55 \mathrm{~nm} \mathrm{SiO} 2$ per lung showed no clinical signs that differed from the control group. Mean body weights measured before instillation, on the first day after instillation, and on day three just before necropsy were also comparable to the control animals (Table 4). The hematological examination revealed a small but significant decrease in platelet counts for $55 \mathrm{~nm} \mathrm{SiO} 2$ and a significant increase in absolute neutrophil counts for $15 \mathrm{~nm} \mathrm{SiO}_{2}$ (Table 5 and Figure 3). In the bronchoalveolar lavage fluid (BALF) of rats treated with $55 \mathrm{~nm} \mathrm{SiO}_{2}$, significant increases in absolute lymphocytes, polymorphonuclear neutrophils (PMNs), atypical cells, and eosinophils were recorded. In the BALF of rats treated with $15 \mathrm{~nm} \mathrm{SiO}_{2}$, the absolute counts of all examined cell types (except for macrophages) were significantly increased. The increased total cell count was mainly attributed to the influx of PMNs and lymphocytes. Consistently, the cytological alterations recorded in the BALF of rats treated with $15 \mathrm{~nm} \mathrm{SiO} 2$ were qualitatively similar but more pronounced than those induced by $55 \mathrm{~nm} \mathrm{SiO}$. Further, the total protein level in the BALF of rats treated with $15 \mathrm{~nm} \mathrm{SiO}_{2}$ was elevated 4.7-fold compared to the control animals, and all measured enzyme activity ( $\gamma$-glutamyltransferase (GGT), LDH, alkaline phosphatase (ALP), and $N$-acetyl- $\beta$-glucosaminidase (NAG)) was increased two- to fivefold. In the BALF of rats treated with $55 \mathrm{~nm} \mathrm{SiO}_{2}$, the total protein level increased 1.9-fold, and LDH and ALP were the only enzymes with significantly increased activity (2.7 and 1.8-fold, respectively) (Table 5 and Figure 3).

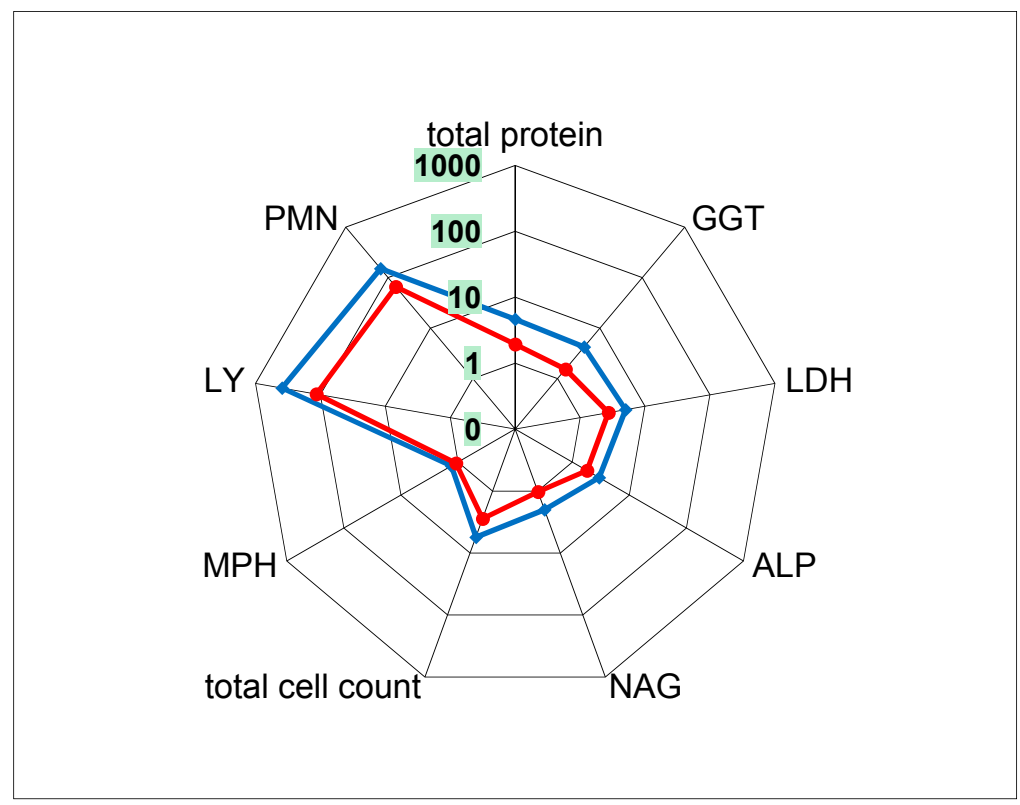

Figure 3. Cell counts, total protein, and enzymes in bronchoalveolar lavage fluid of rats $72 \mathrm{~h}$ after single intratracheal instillation of $360 \mu \mathrm{g} 55 \mathrm{~nm}$ or $15 \mathrm{~nm} \mathrm{SiO}$ (from Maser et al. [59]). Blue line: $15 \mathrm{~nm} \mathrm{SiO} 2$; red: $55 \mathrm{~nm} \mathrm{SiO} 2$. Abbreviations: ALP: alkaline phosphatase; GGT: $\gamma$-glutamyltransferase; LDH: lactate dehydrogenase; LY: absolute cell count for lymphocytes; MPH: absolute cell count for macrophages; PMN: absolute cell count for polymorphonuclear neutrophilic granulocytes; NAG: $N$-acetyl- $\beta$-glucosaminidase.

The observation that $15 \mathrm{~nm} \mathrm{SiO} 2$ elicited more pronounced effects than $55 \mathrm{~nm} \mathrm{SiO}_{2}$ was further underlined by the pathological findings (Table 4). Rats treated with $15 \mathrm{~nm} \mathrm{SiO}$ showed noticeable increases in lung weight (+38\% compared to the control group) and spleen weight (+19\%). Furthermore, they exhibited enlarged mediastinal lymph nodes, most likely due to inflammatory activation. By comparison, treatment with $55 \mathrm{~nm} \mathrm{SiO}_{2}$ led to no such abnormalities. For both treatment groups, the increased lung weight was assessed as being caused by an influx of inflammatory cells and the resulting 
swelling of the tissue due to overall inflammation, and they were consistent with the histopathological examination: in all lung lobes of two of the three animals treated with $55 \mathrm{~nm} \mathrm{SiO}$, mild multifocal granulomatous inflammation with thickening of the alveolar walls was observed, caused by infiltrated macrophages and granulocytes. Again, the lungs of all three rats from the $15 \mathrm{~nm} \mathrm{SiO}_{2}$ treatment group were more severely affected, and mild to severe lympho-reticular hyperplasia of the mediastinal lymph nodes was recorded (data not shown). This microscopic finding is common when lymph nodes are activated by an inflammatory process in the area of drainage, and it was consistent with the macroscopically diagnosed lymph node enlargement (Maser et al. [59]).

Table 4. Effects of $55 \mathrm{~nm}$ and $15 \mathrm{~nm} \mathrm{SiO}_{2}$ in a rat intratracheal instillation study: terminal body weight and organ weight (three animals per group).

\begin{tabular}{|c|c|c|c|c|c|c|}
\hline & & \multirow{2}{*}{ Control Group } & \multicolumn{2}{|c|}{$55 \mathrm{~nm} \mathrm{SiO}_{2}$} & \multicolumn{2}{|c|}{$15 \mathrm{~nm} \mathrm{SiO} 2$} \\
\hline & & & (g) & $\%$ dev & (g) & $\%$ dev \\
\hline \multirow{2}{*}{ Body weight } & Mean & 213.47 & 223.13 & 5 & 216.2 & 1 \\
\hline & $\mathrm{SD}$ & 11.73 & 7.5 & & 5.21 & \\
\hline \multirow{2}{*}{ Kidney } & Mean & 1.58 & 1.7 & 8 & 1.6 & 1 \\
\hline & SD & 0.16 & 0.1 & & 0.11 & \\
\hline \multirow{2}{*}{ Liver } & Mean & 6.54 & 6.95 & 6 & 7.07 & 8 \\
\hline & $\mathrm{SD}$ & 0.69 & 0.27 & & 0.62 & \\
\hline \multirow{2}{*}{ Lung } & Mean & 0.85 & 0.93 & 10 & 1.17 & 38 \\
\hline & SD & 0.04 & 0.09 & & 0.11 & \\
\hline \multirow{2}{*}{ Spleen } & Mean & 0.51 & 0.54 & 7 & 0.61 & 19 \\
\hline & SD & 0.08 & 0.04 & & 0.06 & \\
\hline
\end{tabular}

Abbreviations: dev: deviation (from control group); SD: standard deviation.

Table 5. In vivo rat intratracheal instillation study assessing $55 \mathrm{~nm}$ and $15 \mathrm{~nm} \mathrm{SiO} 2$ : hematology and bronchoalveolar lavage fluid parameters (five animals per group).

\begin{tabular}{|c|c|c|c|c|}
\hline Parameter & \multicolumn{2}{|c|}{$55 \mathrm{~nm} \mathrm{SiO}_{2}$} & \multicolumn{2}{|c|}{$15 \mathrm{~nm} \mathrm{SiO} 2$} \\
\hline \multicolumn{5}{|c|}{ Hematology } \\
\hline WBC & $0.9 \pm 0.4$ & & $1.1 \pm 0.1$ & \\
\hline $\mathrm{RBC}$ & $1.0 \pm 0.0$ & & $1.0 \pm 0.0$ & \\
\hline HGB & $1.0 \pm 0.0$ & & $1.0 \pm 0.0$ & \\
\hline HCT & $1.0 \pm 0.0$ & & $1.0 \pm 0.0$ & \\
\hline $\mathrm{MCV}$ & $1.0 \pm 0.0$ & & $1.0 \pm 0.0$ & \\
\hline $\mathrm{MCH}$ & $1.0 \pm 0.0$ & & $1.0 \pm 0.0$ & \\
\hline $\mathrm{MCHC}$ & $1.0 \pm 0.0$ & & $1.0 \pm 0.0$ & \\
\hline PLT & $0.9 \pm 0.0$ & ** & $1.0 \pm 0.0$ & \\
\hline NEUT & $1.0 \pm 0.4$ & & $1.9 \pm 0.4$ & * \\
\hline LY & $0.9 \pm 0.4$ & & $1.0 \pm 0.1$ & \\
\hline MONO & $0.9 \pm 0.4$ & & $1.1 \pm 0.1$ & \\
\hline EO & $1.0 \pm 0.3$ & & $1.2 \pm 0.5$ & \\
\hline BASO & $1.0 \pm 1.0$ & & $1.0 \pm 1.0$ & \\
\hline LUC & $1.0 \pm 0.5$ & & $1.0 \pm 0.3$ & \\
\hline \multicolumn{5}{|c|}{ Bronchoalveolar lavage fluid } \\
\hline Total cells & $2.8 \pm 0.5$ & $* *$ & $5.5 \pm 1.0$ & $* *$ \\
\hline $\mathrm{MPH}$ & $1.1 \pm 0.4$ & & $1.3 \pm 0.5$ & \\
\hline LY & $155.7 \pm 36.3$ & $* *$ & $391.7 \pm 197.7$ & ** \\
\hline PMN & $66.1 \pm 29.0$ & $* *$ & $151.1 \pm 27.8$ & ** \\
\hline MONO & + & & + & * \\
\hline EO & $9.8 \pm 9.8$ & * & $92.7 \pm 75.9$ & ** \\
\hline ATY & + & * & + & $* *$ \\
\hline
\end{tabular}


Table 5. Cont.

\begin{tabular}{|c|c|c|c|c|}
\hline \multirow{2}{*}{$\begin{array}{c}\text { Parameter } \\
\text { Total protein }\end{array}$} & \multicolumn{2}{|c|}{$55 \mathrm{~nm} \mathrm{SiO} 2$} & \multicolumn{2}{|c|}{$15 \mathrm{~nm} \mathrm{SiO} 2$} \\
\hline & $1.9 \pm 0.5$ & $*$ & $4.7 \pm 0.4$ & $* *$ \\
\hline GGT & $1.5 \pm 0.6$ & & $4.2 \pm 1.1$ & $* *$ \\
\hline $\mathrm{LDH}$ & $2.7 \pm 1.0$ & $* *$ & $5.0 \pm 1.6$ & $* *$ \\
\hline ALP & $1.8 \pm 0.5$ & $* *$ & $2.9 \pm 0.7$ & $* *$ \\
\hline NAG & $1.0 \pm 0.3$ & & $2.0 \pm 0.4$ & $* *$ \\
\hline
\end{tabular}

All values are expressed as fold changes compared to concurrent controls (mean \pm standard deviation). Statistical analysis was performed by two-sided Mann-Whitney $\mathrm{U}$ test (* $p$-value $\leq 0.05 ; * * p$-value $\leq 0.01)$. Abbreviations: ALP: alkaline phosphatase; ATY: atypical cell; BASO: basophil; EO: eosinophil; GGT: $\gamma$-glutamyltransferase; HCT: packed cell volume; HGB: hemoglobin; LDH: lactate dehydrogenase; LUC: large unstained cell; LY: lymphocyte; $\mathrm{MCH}(\mathrm{C})$ : mean corpuscular hemoglobin (concentration); MCV: mean corpuscular volume; MONO: monocyte; MPH: macrophage; NAG: $N$-acetyl- $\beta$-glucosaminidase; NEUT: neutrophil; PLT: platelet; PMN: polymorphonuclear neutrophil; RBC: red blood cell; TP: total protein; WBC: white blood cell.

The pulmonary effects elicited by $15 \mathrm{~nm} \mathrm{SiO} 23$ days after intratracheal administration of a single bolus dose of $360 \mu \mathrm{g} /$ lung were more pronounced than the respective findings in a rat STIS at comparable lung burden (i.e., $342 \mu \mathrm{g}$ shortly after 5-day inhalation exposure to $50 \mathrm{mg} / \mathrm{m}^{3} 15 \mathrm{~nm}$ $\mathrm{SiO}_{2}$ [15]; Box 2). Possibly the high dose rate induced by intratracheal instillation compared to the continuous lower dose rate in the STIS during aerosol administration accounts for the observed difference in pulmonary findings.

Box 2. Rat short-term inhalation toxicity of $15 \mathrm{~nm}-\mathrm{SiO}_{2}$ [15].

In a rat STIS (aerosol administration for 5 consecutive days; $6 \mathrm{~h} /$ day) [15], inhalation exposure to $50 \mathrm{mg} / \mathrm{m}^{3}$ $15 \mathrm{~nm}-\mathrm{SiO}_{2}$ caused a lung burden of $342 \mu \mathrm{g}$ immediately after the 5-day inhalation exposure period and marginal systemic inflammation, evidenced by slight and transient increases in granulocyte counts in the blood. Increased PMN and lymphocyte counts were present in the BALF of this high concentration test group shortly after exposure and (in the 10 and $50 \mathrm{mg} / \mathrm{m}^{3}$ test groups) 3-weeks post-exposure. Histologically, multifocal macrophage aggregates were observed in the lung shortly after exposure. This finding exacerbated towards a slight multifocal pulmonary inflammation by the end of the 3-week post-exposure period. The NOAEC of $15 \mathrm{~nm}-\mathrm{SiO}_{2}$ was assessed as $2.5 \mathrm{mg} / \mathrm{m}^{3}$ [15]. Applying the DF4nanoGrouping threshold (STIS NOAEC < $10 \mathrm{mg} / \mathrm{m}^{3}=(\mathrm{MG} 4)$ active nanomaterial), $15 \mathrm{~nm}-\mathrm{SiO}_{2}$ was assigned as (MG4) active [33].

\subsection{Summary and In Vitro-In Vivo Correlation of the Test Results}

In the in vitro NR8383 AM assay, all four test materials elicited a concentration-dependent release of LDH, GLU, and TNF $\alpha$ (between 5.6 and $45 \mu \mathrm{g} / \mathrm{mL}$ ). Further, the two smaller test materials ( 9 and $15 \mathrm{~nm} \mathrm{SiO}$ ) induced moderate but significant $\mathrm{H}_{2} \mathrm{O}_{2}$ release at the highest nominal concentration $(45 \mu \mathrm{g} / \mathrm{mL})$. As can be seen in Figure 1 and SI, Table S2, the severity of in vitro findings increased with increasing specific surface area of the colloidal $\mathrm{SiO}_{2}$ (and hence decreasing particle size).

Since LDH release, which mirrors cell membrane damage, was determined in the NR8383 AM assay and in the BALF of rats submitted to the intratracheal instillation study, the in vitro and in vivo data obtained for this endpoint were compared (Figure 4). To facilitate in vitro-in vivo comparison, the highest nominal in vitro concentration $(45 \mu \mathrm{g} / \mathrm{mL})$ and the in vivo dose $(360 \mu \mathrm{g} / \mathrm{lung})$ were selected to reflect similar material mass per AM (in vitro: 30 pg/NR8383 AM; in vivo: 36-27 pg/AM in rat lungs; $c f$. Section 4.2). Both in vitro and in vivo, $\mathrm{LDH}$ release was more pronounced for the $15 \mathrm{~nm} \mathrm{SiO}_{2}$ than for the $55 \mathrm{~nm} \mathrm{SiO}_{2}$. Further, for both test materials, the in vitro effects were less pronounced than the in vivo effects, albeit with overlapping standard deviations (Figure 4). Due to the limited database (two test materials), this estimation was not verified by statistical analysis. 


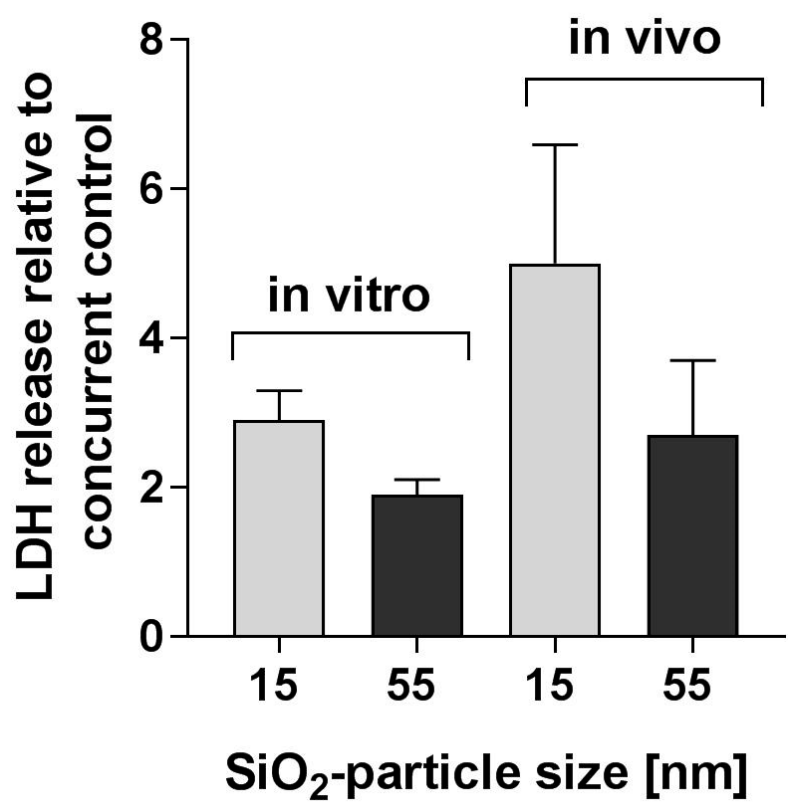

Figure 4. Comparison of in vitro LDH release (NR8383 assay) and in vivo LDH release (rat intratracheal instillation study) elicited by $15 \mathrm{~nm}$ and $55 \mathrm{~nm} \mathrm{SiO}{ }_{2}$. In vitro $\mathrm{LDH}$ release was elicited by $45 \mu \mathrm{g} / \mathrm{mL}$ of either $15 \mathrm{~nm}$ or $55 \mathrm{~nm} \mathrm{SiO}_{2}$ in the NR8383 assay; in vivo LDH release was elicited by a bolus dose of $360 \mu \mathrm{g} /$ lung (intratracheal instillation). The in vitro test material dose (nominally $30 \mathrm{pg} / \mathrm{NR} 8383$ AM or $45 \mu \mathrm{g} / \mathrm{mL}$ ) was selected to reflect the in vivo dose (nominally $27-36 \mathrm{pg} / \mathrm{AM}$ or $360 \mu \mathrm{g} / \mathrm{lung}$ ).

When the two-out-of-four prediction model was applied, expressing test results as surface area-based effective concentrations (estimated by ISDD modelling [66]), all four test materials were assigned as active (MG4) nanomaterials (Table 3). (When expressing test results as nominal concentrations, only $30 \mathrm{~nm}$ and $55 \mathrm{~nm} \mathrm{SiO} 2$ were assessed as active (MG4).) The available in vivo data support the overall appraisal of colloidal $\mathrm{SiO}_{2}$ as active, and hence the use of effective concentrations for the overall evaluation: Applying the DF4nanoGrouping STIS-related threshold (MG4 indicated by a STIS NOAEC below $10 \mathrm{mg} / \mathrm{m}^{3}$ [32,33]), $15 \mathrm{~nm} \mathrm{SiO}_{2}$ was assigned as active (MG4) (STIS NOAEC: $2.5 \mathrm{mg} / \mathrm{m}^{3}$ [15]; Box 2). STIS data are unavailable for the other three test materials. While the DF4nanoGrouping does not include an evaluation scheme for intratracheal instillation data, the pulmonary effects elicited by $55 \mathrm{~nm}$ and $15 \mathrm{~nm} \mathrm{SiO}_{2}$ in the intratracheal instillation study strongly support the in vitro assessment that these test materials are active (MG4).

\section{Discussion}

The present study aimed at assessing four extensively characterized colloidal $\mathrm{SiO}_{2}$ (PPS: $9 \mathrm{~nm}$, $15 \mathrm{~nm}, 30 \mathrm{~nm}$, and $55 \mathrm{~nm}$ ) by the NR8383 AM assay and comparing the in vitro findings to in vivo pulmonary effects elicited by $15 \mathrm{~nm}$ and $55 \mathrm{~nm} \mathrm{SiO}_{2}$ in a rat intratracheal instillation study (3 days after administration of a single bolus dose) and available rat STIS data for $15 \mathrm{~nm} \mathrm{SiO}_{2}$. The study served the overarching goal of identifying intrinsic material properties and system-dependent properties of colloidal $\mathrm{SiO}_{2}$ that may affect its in vitro and in vivo pulmonary toxicity (further discussed in Section 3.1) and further elucidating the applicability of the NR8383 AM assay published by Wiemann et al. [22] in predicting the pulmonary toxicity of well-dispersed colloidal amorphous $\mathrm{SiO}_{2}$. Section 3.2 discusses the test materials' in vitro effective concentrations and Section 3.3 their in vitro effects on NR8383 AMs; Section 3.4 further assesses the in vitro effects of different amorphous $\mathrm{SiO}_{2}$, and Section 3.5 provides an in vitro-in vivo comparison of the findings. 


\subsection{Relevant Intrinsic Material and System-Dependent Properties of Colloidal Amorphous $\mathrm{SiO}_{2}$}

All four test materials were extensively characterized to yield data for all grouping criteria of both tiers of the DF4nanoGrouping (Box 1): the intrinsic material properties water solubility, particle morphology, and chemical composition (Tier 1), and the system-dependent properties dissolution rate in biological media, surface reactivity, and particle dispersibility (Tier 2) [32,33].

Water solubility of the test materials decreased with increasing PPS (from $48 \mathrm{mg} / \mathrm{L}$ for $9 \mathrm{~nm} \mathrm{SiO}_{2}$ to $7 \mathrm{mg} / \mathrm{L}$ for $55 \mathrm{~nm} \mathrm{SiO}_{2}$; Table 1) and remained well below the DF4nanoGrouping threshold of $100 \mathrm{mg} / \mathrm{L}[32,33]$. Consistent with these findings, a low dissolution rate in phagolysosomal simulant fluid was recorded that was again inversely proportional to PPS (Table 1). In consequence, none of the test materials were assigned as soluble (MG1) nanomaterials.

All four colloidal $\mathrm{SiO}_{2}$ remained well dispersed in F-12K medium, KRPG buffer, and 0.9\% $\mathrm{NaCl}$ solution (Table 1). The pronounced dispersibility in protein-free media is highly relevant for in vitro dosimetry. Further, within the DF4nanoGrouping, high dispersibility indicates potential in vivo mobility, resulting in a precautionary assignment of such nanomaterials as active (MG4) [32,33]. However, high dispersibility in protein-free media may overestimate intrapulmonary mobility. Notably, $15 \mathrm{~nm}$ and $55 \mathrm{~nm} \mathrm{SiO}{ }_{2}$ strongly agglomerated in DMEM + FCS (Table 2), indicating nonmobility, whereas dispersibility was not assessed in other protein-containing fluids that more closely resembled the in vivo lung lining fluid.

The specific surface reactivity of colloidal amorphous $\mathrm{SiO}_{2}$ (assessed by surface-induced biological oxidative damage and expressed as $\mathrm{nM}$ Trulox equivalent units per $\mathrm{m}^{2}$ nanomaterial) was significantly above zero. Nevertheless, for all four colloidal $\mathrm{SiO}_{2}$ it was consistently below $10 \%$ of the reactivity of strongly oxidative $\mathrm{Mn}_{2} \mathrm{O}_{3}$ nanoparticles. Hence, the specific surface reactivity of colloidal $\mathrm{SiO}_{2}$ did not indicate activity (MG4) according to this DF4nanoGrouping threshold [32,33].

In contrast to the NR8383 AM assay (and other in vitro test methods), abiotic test methods to determine surface reactivity (e.g., surface-induced biological oxidative damage, electron spin resonance, or ferric-reducing ability of serum) do not require gravitational sedimentation of the test materials but are performed under constant stirring. Therefore, abiotic test methods might provide relevant data to prevent false negative in vitro test results for materials that are actually active (MG4) but too well dispersed to reach the bottom of the wells or the cultured cells. Despite this, the results from the present study show that the cellular effects elicited by colloidal $\mathrm{SiO}_{2}$ in the NR8383 AM assay were not predominantly elicited by its oxidative surface reactivity.

Based on evaluation of the DF4nanoGrouping Tier 1 and Tier 2 grouping criteria $[32,33]$ the four colloidal $\mathrm{SiO}_{2}$ are assigned as active (MG4) on account of their dispersibility (and the cellular effects observed in the NR8383 AM assay, as further discussed in Section 3.3).

\subsection{In Vitro Effective Concentration}

In Wiemann et al. [22], which first described the NR8383 AM assay, the vast majority of test materials underwent rapid gravitational settling and could therefore be engulfed by the NR8383 AMs. Accordingly, the effective concentration of these materials was considered to be consistent with their nominal (total applied) concentration. This provided a good starting point for the overall successful in vitro-in vivo comparison, and for the well-dispersed nonsettling $15 \mathrm{~nm} \mathrm{SiO}{ }_{2}$, even though those authors did not correct the corresponding in vitro results for the effective concentration (cf. Table 3 of the present study, bottom row).

In the present study, the four colloidal $\mathrm{SiO}_{2}$, which differed only by PPS, elicited concentrationand inversely size-dependent effects in the NR8383 AM assay. To account for the high dispersibility of the test materials in interpreting the in vitro findings, the in vitro effective concentrations were estimated. Based on ISDD modelling [66], the effective concentrations ranged from $15.8 \%$ for the $55 \mathrm{~nm} \mathrm{SiO}{ }_{2}$ to $31.0 \%$ for the $9 \mathrm{~nm} \mathrm{SiO}_{2}$. Hence, the transport prediction by ISDD is dominated by diffusion. By comparison, the AUC measurements, which suppress the contribution of diffusion transport and determine only sedimentation transport, overall indicated only minimal gravitational 
settling of all tested colloidal amorphous $\mathrm{SiO}_{2}$ in protein-free media. However, an approximately 10-fold more pronounced sedimentation was recorded for the $55 \mathrm{~nm} \mathrm{SiO} 2$ (4.3\% after $24 \mathrm{~h})$ than for the $9 \mathrm{~nm} \mathrm{SiO} 2(0.4 \%)$ (SI, Table S1 and Figure S1). In contrast to particle sedimentation (larger particles sediment more quickly than smaller ones), particle diffusion is inversely proportional to particle size. The observation that the smaller colloidal $\mathrm{SiO}_{2}$ elicited more pronounced in vitro effects than the larger might be interpreted as higher effective dose of the smaller sized particles due to their transport by diffusion.

However, the in vitro effective concentration of nanomaterials is also influenced by the proportion of nanoparticles that adhere to the bottom of the wells, i.e., gathered within the reach of the cultured cells [56-58,66,67]. Since the ISSD model assumes a "sticky" lower boundary condition, i.e., a probability of 1 that nanoparticles that come close to the cultured cells adhere to them, and since both colloidal $\mathrm{SiO}_{2}$ and cell surfaces are negatively charged, it might overestimate the effective concentration, possibly to different extents for different particles [67]. The one-dimensional distorted grid (DG) model allows adjusting the probability for nanoparticle adherence by including either a "sticky" or "reflective" bottom assumption $[67,68]$. When the sticky bottom assumption is selected, every particle that touches the bottom of the well due to diffusion is counted as sedimented. This results in a greater weighting of movement by diffusion during the modelling. By contrast, when the reflective bottom assumption is selected, particles that touch the bottom of the well are not counted as sedimented [68]. DG modelling was performed to further investigate how the probability of particle adherence to the bottom of the wells affected the in vitro effective concentrations of the four colloidal $\mathrm{SiO}_{2}$. The DG model-based effective concentrations matched the ISDD model-based predictions in terms of both absolute levels and size-dependent ranking of the colloidal $\mathrm{SiO}_{2}$ (Table 2) if the sticky bottom assumption was selected (SI, Figure S2A). If the DG model was applied using the reflective bottom assumption [68], the AUC measurements of the sedimented proportion of test materials (SI, Figure S1) matched the DG model-based effective concentrations in terms of both absolute levels and size-dependent ranking of the colloidal $\mathrm{SiO}_{2}$ (SI, Figure S2B).

Based on these calculations, and further considering that a concrete value for the stickiness of an NR8383 AM culture is not yet available, it was decided to use the ISDD-based estimations (and hence the sticky bottom assumption) to evaluate the in vitro results in spite of limitations of the ISDD model in calculating effective concentrations of colloidal $\mathrm{SiO}_{2}$ highlighted by the developers of the DG model (Phil Demokritou, Harvard University, Cambridge, MA, USA; personal communication, 2017).

By contrast, the DG model-based estimations applying the reflective bottom assumption (and, concordantly, the AUC measurements) were assessed as underrating the "true" effective concentrations. Considering that all four colloidal $\mathrm{SiO}_{2}$ elicited concentration-dependent cellular effects, effective concentrations ranging below $1 \%$ (at $16 \mathrm{~h}$ ) would point to very toxic test materials. However, the available in vivo studies provide no indication for such high toxicity. Taken together, these observations can be interpreted as indicating that the probability of particles reflecting from the direct vicinity of cells is neither 0 nor 1 , but somewhere in between. Presumably, the "true" effective concentration of the test materials in the NR8383 AM assay ranged between the (DG or ISDD model-based) sticky bottom and reflective bottom assumption estimations (and hence the AUC data). In this regard, it would be important to consider and include the highly evolved particle uptake mechanisms of macrophages into realistic models predicting the in vitro effective dose.

In summary, these observations highlight the need to consider in vitro dosimetry when in vitro test systems are used to assess nanomaterials of high dispersion stability, but also the challenges that such considerations entail. This caveat applies especially to colloidal $\mathrm{SiO}_{2} \mathrm{when}_{\text {dispersed in }}$ protein-free media, but does not, in general, extend to pyrogenic or precipitated $\mathrm{SiO}_{2}$, which has much lower dispersion stability. To the best of the authors' knowledge, a test method that allows quantitatively determining the proportion of nanoparticles making up the effective dose, i.e., within and/or upon the cells, is not yet available. For specifically designed nanomaterials, stimulated emission depletion microscopy might be a suitable method to enable such measurements [69]. Further, fluorescence 
labelling of the test materials enables qualitatively investigating in vitro cellular uptake. Previous studies with fluorescent colloidal $\mathrm{SiO}_{2}$ showed a fluorescent halo at the outer membrane of NR8383 AMs (data not shown), suggesting that NR8383 AM cells may indeed provide a sticky surface structure for colloidal $\mathrm{SiO}_{2}$. Such a structure might enhance cellular uptake of the test materials, and hence elicitation of cellular effects ( $c f$. also Section 3.4).

When estimating in vitro effective concentrations, the assumptions underlying the calculations (in terms of particle sedimentation, diffusion, and adherence to the cells) should be specified and the strengths and limitations of the applied model identified. The ensuing uncertainties related to the calculated effective concentrations should be addressed in the evaluation of in vitro test results [70]. For the NR8383 AM assay specifically, whenever the two-out-of-four prediction model yields different results using nominal concentration-based or effective concentration-based results, the calculated effective concentration-based in vitro LOAECs should be used for the overall evaluation. At present, the ISDD model [66] appears to provide a reasonable upper estimate of the effective concentration, yielding a conservative approach for hazard and risk assessment.

\subsection{In Vitro Effects of Colloidal Amorphous $\mathrm{SiO}_{2}$}

All four test materials clearly elicited concentration-dependent release of LDH, GLU, and TNF $\alpha$ in the NR8383 AM assay, and the two smaller test materials further elicited significant $\mathrm{H}_{2} \mathrm{O}_{2}$ release at the highest nominal concentration ( $45 \mu \mathrm{g} / \mathrm{mL}$; SI, Table S2). This observation that the smaller $9 \mathrm{~nm}$ and $15 \mathrm{~nm} \mathrm{SiO}{ }_{2}$ elicited more pronounced in vitro effects than the larger $55 \mathrm{~nm}$ and $30 \mathrm{~nm} \mathrm{SiO}_{2}$ is consistent with the outcome of the in vivo intratracheal instillation study, where $15 \mathrm{~nm} \mathrm{SiO}_{2}$ elicited more severe pulmonary effects than $55 \mathrm{~nm} \mathrm{SiO}_{2}$ (Tables 4 and 5).

When $\mathrm{TNF} \alpha$ release was plotted jointly for all four colloidal $\mathrm{SiO}_{2}$, more stringent dose-response curves were obtained when the effective (ISDD-modelled) and nominal test material concentrations were expressed in surface area-based metrics $\left(\mathrm{mm}^{2} / \mathrm{L}\right.$; Figure 2). Interestingly, this was not obtained for LDH or GLU release (data not shown). This suggests that TNF $\alpha$ release is attributable to the test material's surface properties, rather than mass, whereas LDH or GLU release partly or entirely depends on other intrinsic or system-dependent properties. TNF $\alpha$ induction upon in vitro administration of amorphous $\mathrm{SiO}_{2}$ is known to involve particle uptake as well as secondary adenosine signaling and NLRP3 proteasome activation [71].

In the present study, the amount of released TNF $\alpha$ was measured by ELISA. By comparison, Wiemann et al. [22] used the L929 cytolysis test [72] to measure the bioactive TNF $\alpha$ induced in the supernatant of the treated NR8383 AMs. ELISA was considered preferable, as it rules out direct cellular effects of nonsedimented colloidal $\mathrm{SiO}_{2}$ nanoparticles on $\mathrm{L} 929$ cells.

For overall evaluation of the test results from the NR8383 AM assay, Wiemann et al. [22] set a threshold of $6000 \mathrm{~mm}^{2} / \mathrm{mL}$ to distinguish between test material-specific effects and effects caused by unspecific cellular overload. This threshold was calculated as being the highest particle surface area-based concentration that does not yet result in particle overload of the NR8383 AMs. The threshold was expressed in surface area-based metrics, since the effects of nanomaterials, when applied under non-cellular-overload conditions, appear to be mainly conveyed by particle surface, not particle mass [45,73-75]. Rushton et al. [19] showed that in vitro studies with AMs (assessing ROS generation) correlated significantly with in vivo rat intratracheal instillation studies (measuring PMN counts $24 \mathrm{~h}$ after instillation) when biological activity was expressed by particle surface area metrics.

Using effective concentration-based in vitro LOAECs in the two-out-of-four prediction model (described by Wiemann et al. [22] for overall evaluation of the outcome of the NR8383 AM assay), all four test materials were assessed as active (MG4) (Table 3). In contrast, when nominal concentration-based in vitro LOAECs were used, only the two larger test materials $(30 \mathrm{~nm}$ and $55 \mathrm{~nm} \mathrm{SiO} 2$ ) were assessed as active (MG4), whereas $15 \mathrm{~nm}$ and $9 \mathrm{~nm} \mathrm{SiO}{ }_{2}$ exhibited effects only above the threshold of $6000 \mathrm{~mm}^{2} / \mathrm{mL}$, indicating cellular overload (i.e., in vitro LOAECs of $6750 \mathrm{~mm}^{2} / \mathrm{mL}$ for both LDH and GLU release; Table 3). These nominal concentration-based results might also be 
interpreted as borderline non-cellular overload, and therefore inconclusive, effects. As highlighted by Leontaridou et al. [70], in vitro test methods (just as any other test method) inherently have a borderline range around their classification threshold within which test results are inconclusive due to the test method's biological and technical variability.

In summary, the particle surface area-based threshold of $6000 \mathrm{~mm}^{2} / \mathrm{mL}$ [22] proved useful to assess the activity of colloidal $\mathrm{SiO}_{2}$ using ISDD-modelled effective concentration-based test results. Nevertheless, as further knowledge becomes available on how the intrinsic material properties of nanomaterials affect their in vitro and in vivo toxicity, this surface area-based threshold and the two-out-of-four prediction model may need to be refined and adapted to take into account further material properties that may affect the in vitro or in vivo effects of specific types of nanomaterials.

\subsection{Further In Vitro Studies Investigating Colloidal $\mathrm{SiO}_{2}$ and Other Amorphous $\mathrm{SiO}_{2}$}

In the NR8383 AM assay, protein-free media (i.e., F-12K medium and KRPG buffer) are used to prevent particle agglomeration. By contrast, media containing, e.g., lipids, surfactant proteins, or serum proteins destabilize colloidal test materials, resulting in particle agglomeration [55,76-79]. The degree of agglomeration affects the nanoparticles' sedimentation in vitro (cf. Section 3.2), and hence the manner in which they come into contact with the cultured cells [80]. However, the cellular uptake of colloidal $\mathrm{SiO}_{2}$ nanoparticles also appears to depend on the type of cultured cells [81], and noninternalized particles can also damage the cell membrane, and hence induce cellular effects, by diffusion contact [74,82].

Further, numerous studies have concluded that the in vitro toxicity of amorphous $\mathrm{SiO}_{2}$ nanomaterials is mitigated in the presence of serum supplements [6,83-86]. Despite this, when prepared in cell culture media supplemented with $10 \%$ FCS, the four colloidal amorphous $\mathrm{SiO}_{2}$ tested in the present study induced different forms of genotoxicity in the alkaline Comet assay using V79 cells or precision-cut rat lung slices and in the alkaline unwinding assay using A549 cells [59]. Using EpiAirway ${ }^{\mathrm{TM}}$ 3D human bronchial models maintained in EpiAirway ${ }^{\mathrm{TM}}$ culture medium not supplemented with serum ( $c f$. https:/ / www.mattek.com/products/epiairway/), $15 \mathrm{~nm} \mathrm{SiO}_{2}$ (as used in the present study) and $15 \mathrm{~nm} \mathrm{SiO}_{2}$ with phosphonate surface functionalization induced marginal but still significant genotoxicity in the alkaline Comet assay at $50 \mu \mathrm{g} / \mathrm{cm}^{2}$ tissue, but no cytotoxicity in either the LDH or adenosine triphosphate assay [87]. However, ex vivo, neither $15 \mathrm{~nm}$ nor $55 \mathrm{~nm} \mathrm{SiO} 2$ caused genotoxic effects in lung or bone marrow cells [59] from rats submitted to the intratracheal instillation study described here.

In addition, $15 \mathrm{~nm}$ and $55 \mathrm{~nm} \mathrm{SiO} 2$ were assessed in a 3D reconstructed skin micronucleus assay using EpiDerm ${ }^{\mathrm{TM}}$ tissue maintained in the supplier's growth medium [88], also not supplemented with serum (cf. https:/ / www.mattek.com/products/epiderm/). Test material cellular uptake analysis revealed no exposure of $15 \mathrm{~nm}$ or $55 \mathrm{~nm} \mathrm{SiO}_{2}$ to the EpiDerm ${ }^{\mathrm{TM}}$ cells upon topical application (and hence no cytotoxicity or genotoxicity) and confounding barrier effects of the collagen cell attachment layer during in-medium exposure [88]. By contrast, $15 \mathrm{~nm}$ and $55 \mathrm{~nm} \mathrm{SiO} 2$ were extensively taken up into two-dimensional TK6 cell cultures (cultured in RPMI 1640 medium $+10 \%$ horse serum), where they caused genotoxicity and cytotoxicity [88].

While the NR8383 AM assay does not use serum supplements, nanoparticles in the lung may become coated with proteins/and or lipids from the lung lining fluid over time, and this can facilitate nanoparticle agglomeration inside the alveoli. The degree of agglomeration in lung surfactants likely influences nanoparticle uptake into AMs, and thereby also nanoparticle clearance and toxicity [55]. In spite of the substantial differences between the in vivo lung and the NR8383 AM test system, the serum-free approach of the NR8383 AM assay has proven useful in distinguishing passive (MG3) from active (MG4) nanomaterials [22]. The present study adds further evidence confirming the usefulness of the NR8383 AM assay for assessing colloidal $\mathrm{SiO}_{2}$, while highlighting the need to consider the effective concentration of such test materials with limited gravitational settling. 


\subsection{In Vitro-In Vivo Correlations of the Test Results}

For four differently sized but otherwise identical colloidal $\mathrm{SiO}_{2}$, the present study yields quantitative in vitro data for four parameters ( $\mathrm{LDH}, \mathrm{GLU}, \mathrm{H}_{2} \mathrm{O}_{2}$, and TNF $\alpha$ release) and, for two of the test materials, quantitative in vivo data for a spectrum of BALF parameters (differential cell counts, total protein, and LDH, GGT, ALP, and NAG activity). Although the highest in vitro and in vivo nominal doses per AM were similarly in the range of 27-36 pg/AM (cf. Section 4.2), the differences in the in vitro and in vivo test designs (e.g., with respect to dose rate, time point of recording post-application, fluid volume) must be considered when comparing the results. Regardless of such differences, both the in vitro and in vivo effects elicited by $15 \mathrm{~nm} \mathrm{SiO} 2$ were generally more pronounced than those induced by $55 \mathrm{~nm} \mathrm{SiO}_{2}$ (Figures 1 and 3; Tables 4 and 5). Therefore, the relative differences between the in vivo and in vitro effects of these two test materials (at nominal concentrations of $45 \mu \mathrm{g} / \mathrm{mL}$ ) were further evaluated, revealing that the relative differences (expressed as fold increase induced by $15 \mathrm{~nm} \mathrm{SiO} 2$ compared to $55 \mathrm{~nm} \mathrm{SiO}_{2}$ ) were very similar for a broad spectrum of parameters:

- In vitro: TNF $\alpha$ : 1.9-fold; GLU: 2.1-fold; $\mathrm{H}_{2} \mathrm{O}_{2}$ : 3-fold.

- In vivo (BALF): ALP: 1.6-fold; NAG: 2-fold; total protein: 2.4-fold; GGT: 2.8-fold; inflammatory cells: 1.2-fold to 2.5-fold (Table S2 and Table 5). Only the increase of eosinophils in BALF was exceptionally high (10-fold). This alteration could not be explained.

A direct in vitro and in vivo comparison is shown for $\mathrm{LDH}$ relative to the respective controls (Figure 4). Taking into account the standard deviation of these values, the relative differences of the LDH release in vitro and in vivo induced by $15 \mathrm{~nm}$ and $55 \mathrm{~nm} \mathrm{SiO} 2$ were very similar, although apparently more pronounced in BALF from the lungs of test material-treated rats (Figure 4). A reason for this difference might be that, as outlined above, the in vitro effective concentration may differ from the nominal concentration, whereas inside the lung all particles will contact lung parenchymal structures, i.e., the alveolar inner surface, once the instillation fluid is resorbed. Therefore, the effective dose upon intratracheal instillation was most likely identical with the nominal dose, and differences in the in vivo short-term pulmonary effects induced by $15 \mathrm{~nm}$ and $55 \mathrm{~nm} \mathrm{SiO}$ can be attributed to the fourfold difference in the BET-specific surface area between the two $\left(200 \mathrm{~m}^{2} / \mathrm{g}\right.$ and $50 \mathrm{~m}^{2} / \mathrm{g}$, respectively; Table 1 ).

The differences between in vitro and in vivo LDH release might also be explained by differences in the dose rates of the different test methods. In vivo, differences in dose rates have been shown to affect the severity of pulmonary findings [89]. Generally, at the same lung burden, the dose rate is higher in intratracheal instillation studies (bolus dose application) than in inhalation studies (longer-term inhalation exposure). Similarly, at the same burden per AM, the dose rate in the intratracheal instillation study, where a small volume of test material preparations reached the much larger surface of the lung almost immediately, was much higher than in the NR8383 AM assay, where the particles predominantly reached the cells by diffusion over a longer period of time (i.e., the $16 \mathrm{~h}$ incubation period). Further, in vivo, LDH can be released not only by AMs, but also by other pulmonary cells (e.g., epithelial cells), and the microenvironment of the airway lumen has a considerable influence on many aspects of AM function [90]. By contrast, the in vitro test system used in the NR8383 AM assay only includes AMs. Finally, LDH has been observed to bind onto the surface of nanomaterials in protein-free media, adulterating the detection of test material-induced cell membrane damage [91].

When the two-out-of-four prediction model was applied for overall evaluation of the outcome of the NR8383 AM assay expressing test results as surface area-based effective concentrations (estimated by ISDD modelling), all four test materials were assigned as active (MG4) nanomaterials (Table 3). This is consistent with the available rat STIS data yielding a NOAEL of $2.5 \mathrm{mg} / \mathrm{m}^{3}$ for $15 \mathrm{~nm} \mathrm{SiO}_{2}$ [15], on account of which this material was assigned as active (MG4), applying the DF4nanoGrouping Tier 3 threshold of STIS NOAEC $<10 \mathrm{mg} / \mathrm{m}^{3}$ [32,33]. While that grouping does not include an evaluation scheme for intratracheal instillation data, the pulmonary effects elicited by $55 \mathrm{~nm}$ and $15 \mathrm{~nm} \mathrm{SiO}_{2}$ in 
the intratracheal instillation study strongly support the in vitro assessment that these test materials are active (MG4).

Notably, the assignment of colloidal amorphous $\mathrm{SiO}_{2}$ as active (MG4) is relevant for the inhalation route of exposure, but this assessment cannot be extrapolated to other routes of exposure, or to other types of amorphous $\mathrm{SiO}_{2}$. Buesen et al. [92] did not record any treatment-related adverse effects of $15 \mathrm{~nm} \mathrm{SiO} \mathrm{S}_{2}$ (without or with different surface functionalizations) in rats upon 28-day oral administration (OECD TG 407). Hofmann et al. [93] and Wolterbeek et al. [94] observed no reproductive or developmental toxicity of precipitated $\mathrm{SiO}_{2}$ in rats (OECD TG 414 and 416, respectively); and Kolle et al. [95] reported no in vitro eye-irritating potential of either precipitated or pyrogenic $\mathrm{SiO}_{2}$ in the bovine corneal opacity and permeability assay (OECD TG 437) or the reconstructed human cornea-like epithelium test method (OECD TG 492).

In DF4nanoGrouping case studies [33], a precipitated amorphous $\mathrm{SiO}_{2}$ and a pyrogenic amorphous $\mathrm{SiO}_{2}$ were assigned as borderline (MG1) soluble nanomaterials, since they were partially soluble in water and DMEM supplemented with $10 \%$ FCS, but highly soluble in Gamble's solution. By contrast, $15 \mathrm{~nm} \mathrm{SiO} 2$ was not water soluble and did not dissolve in biological media, and it was assigned as active (MG4) on account of its in vitro cellular effects, confirmed by the Tier 3 rat STIS data. Further, four surface-functionalized variants of $15 \mathrm{~nm} \mathrm{SiO}_{2}$ were assessed; two were assigned as passive (MG3) and two as active (MG4) nanomaterials

In summary, the high degree of coincidence between the in vitro and in vivo results obtained for $15 \mathrm{~nm}$ and $55 \mathrm{~nm} \mathrm{SiO} 2$ underlines the predictive capacity of the NR8383 AM assay. Nevertheless, the pathophysiology of the lung is clearly far more complex, since many more cell types are compromised, as is reflected by the release of cell type-specific enzymes and the presence of invading cells, such as PMNs and eosinophils, in BALF.

\section{Materials and Methods}

\subsection{Test Materials and Test Material Characterization}

The test materials $9 \mathrm{~nm} \mathrm{SiO}, 15 \mathrm{~nm} \mathrm{SiO}_{2}, 30 \mathrm{~nm} \mathrm{SiO}_{2}$, and $55 \mathrm{~nm} \mathrm{SiO}_{2}$ were produced as $30 \%$, $40 \%, 45 \%$, and $50 \%$ suspensions, respectively, by AkzoNobel AB (Bohus, Sweden; formerly H.C. Starck $\mathrm{GmbH}$, Leverkusen, Germany). The particle size distribution was determined by AUC or dynamic light scattering, as described by Wohlleben [41] and Wohlleben et al. [96]. To determine water solubility, forced filtration through $5 \mathrm{kDa}$ filters at $\mathrm{pH} 7$ was applied $[60,97]$. For this purpose, the original test material suspensions were diluted to $10 \mathrm{mg} / \mathrm{mL}$ to prevent filter clogging. Dissolution rate was determined as described by Wohlleben et al. [98]. Surface chemistry and specific surface reactivity were determined by X-ray photoelectron spectroscopy and surface-induced biological oxidative damage, respectively, as described by Gandon et al. [62]. Table 1 provides further details on the test material characterization.

\subsection{Dose Setting and In Vitro Effective Concentration}

The highest test material concentration applied in the NR8383 AM assay and dose applied in the rat intratracheal instillation study were calculated to reflect an aerosol concentration of $50 \mathrm{mg} / \mathrm{m}^{3}$ in the rat STIS. In the rat STIS, inhalation exposure to $50 \mathrm{mg} / \mathrm{m}^{3} 15 \mathrm{~nm} \mathrm{SiO}{ }_{2}$ for $6 \mathrm{~h}$ a day on 5 consecutive days resulted in a lung burden of $342 \mu \mathrm{g}$ [15]. Accordingly, for the intratracheal instillation study, a bolus dose of $360 \mu \mathrm{g} /$ lung was selected.

In order to transfer the in vivo dose to the in vitro dose, the test material content per AM was calculated. The macrophage population per rat lung ranges between $10 \times 10^{6}$ and $13 \times 10^{6}$ cells for rats weighing 200-300 g [25,99,100]. Considering a consistent, complete deposition of instilled material and complete uptake by macrophages, $360 \mu \mathrm{g} 15 \mathrm{~nm} \mathrm{SiO} 2$ per lung corresponds to 36-27 pg test material per AM. To meet this concentration range, $30 \mathrm{pg} / \mathrm{AM}$ was selected as the highest nominal dose in the in vitro NR8383 AM assay. Calculated with a volume of $200 \mu \mathrm{L} /$ well and a defined population 
of $3 \times 10^{5}$ cells/well, this corresponds to a concentration of $45 \mu \mathrm{g} / \mathrm{mL}$. Accordingly, $45 \mu \mathrm{g} / \mathrm{mL}$ was selected as the highest test material concentration in the NR8383 AM assay.

For data evaluation, particle mass-based test material concentrations were converted to particle surface area-based concentrations identified as most suitable for the NR8383 AM assay [22]. For this purpose, the applied particle mass-based concentrations $(\mu \mathrm{g} / \mathrm{mL})$ were multiplied with the respective test material's surface area $\left(\mathrm{m}^{2} / \mathrm{g}\right)$ as assessed by the BET method. This conversion resulted in the dose metric of particle surface area per volume $\left(\mathrm{mm}^{2} / \mathrm{mL}\right)$ (Table 2).

The in vitro effective concentration was calculated using the ISDD model [66] with the following parameters: dish depth: $0.006 \mathrm{~m}$; volume: $0.2 \mathrm{~mL}$; viscosity $\left(\mathrm{H}_{2} \mathrm{O}, 37^{\circ} \mathrm{C}\right): 0.00074 \mathrm{mPa}$; t temperature: $310 \mathrm{~K} ; \mathrm{SiO}_{2}$ density: $2.3 \mathrm{~g} / \mathrm{mL}$; particle size in $\mathrm{F}-12 \mathrm{~K}$ medium ( $c f$. Table 1 ) equals agglomerate size; incubation time: $16 \mathrm{~h}$; packing factor: 0.64 ; fractal dimension: 42,796.00. Test material sedimentation was assessed by AUC as described by Sauer et al. [78].

\subsection{In Vitro NR8383 AM Assay}

NR8383 AMs (ATCC, USA; ATCC ${ }^{\circledR}$ No.: CRL-2192TM) were maintained in F-12K cell culture medium (Sigma-Aldrich, Taufkirchen, Germany) supplemented with 15\% fetal calf serum (FCS), $1 \%$ penicillin/streptomycin, and 1\% L-glutamine (all from PAN Biotech, Aidenbach, Germany), as described in [22]. For testing, cells were seeded into 96 -well plates $\left(3 \times 10^{5}\right.$ cells $/$ well $)$ and kept at $37^{\circ} \mathrm{C}$ and $5 \% \mathrm{CO}_{2}$. Each well contained $200 \mu \mathrm{L}$ F-12K cell culture medium in which the concentration of FCS was reduced to $5 \%$. After $24 \mathrm{~h}$, the medium was replaced by the test material preparations [22].

To determine $\mathrm{H}_{2} \mathrm{O}_{2}$ synthesis and release, the test materials were suspended in KRPG buffer $\left(129 \mathrm{mM} \mathrm{NaCl}, 4.86 \mathrm{mM} \mathrm{KCl}, 1.22 \mathrm{mM} \mathrm{CaCl}_{2}, 15.8 \mathrm{mM} \mathrm{NaH}_{2} \mathrm{PO}_{4}, 5-10 \mathrm{mM}\right.$ glucose; $\mathrm{pH}$ 7.3-7.4). To determine extracellular release of $\mathrm{LDH}, \mathrm{GLU}$, and $\mathrm{TNF} \alpha$, the test materials were suspended in serum-free F-12K cell culture medium (in F-12K assay medium). The suspensions were diluted in the respective fluids to achieve a concentration of $180 \mu \mathrm{g} / \mathrm{mL}$ KRPG buffer or F-12K assay medium, ultrasonicated at $50 \mathrm{~W}$ for $10 \mathrm{~s}$ with a probe (VibraCell ${ }^{\mathrm{TM}}$, Sonics \& Materials, Danbury, CT, USA), and serially diluted with KRPG buffer or F-12K assay medium to achieve concentrations of 45, 22.5, 11.2, and $5.6 \mu \mathrm{g} / \mathrm{mL}$. All tests were performed in triplicate.

\subsection{1. $\mathrm{H}_{2} \mathrm{O}_{2}$ Synthesis}

$\mathrm{H}_{2} \mathrm{O}_{2}$ synthesized by NR8383 AMs and released into the supernatant was quantified in the Amplex $\operatorname{Red}^{\circledR}$ assay as described by Wiemann et al. [22]; zymosan $(180 \mu \mathrm{g} / \mathrm{mL})$ was used as a positive control (all reagents: Sigma-Aldrich). After $90 \mathrm{~min}$ incubation, formation of resorufin was determined. Optical density was measured photometrically (Tecan Infinite F200Pro; absorption: $570 \mathrm{~nm}$; reference value: $620 \mathrm{~nm}$ ), corrected for background absorbance of cell free-particle controls and converted into absolute concentrations of $\mathrm{H}_{2} \mathrm{O}_{2}$ using the molar extinction coefficient of resorufin $\left(54,000 \mathrm{~L} \mathrm{~mol}^{-1} \mathrm{~cm}^{-1}\right)$.

\subsubsection{LDH and GLU Release}

LDH activity was determined after $16 \mathrm{~h}$ test material incubation using a Roche Cytotoxicity Kit (Sigma-Aldrich) as described by the manufacturer. The induced color change was measured photometrically with an Infinite F200Pro plate reader (Tecan Deutschland GmbH, Crailsheim, Germany). To measure GLU activity, $50 \mu \mathrm{L}$ of the supernatant (sampled after $16 \mathrm{~h}$ incubation) was incubated under standard cell culture conditions with $100 \mu \mathrm{L} 0.2 \mathrm{M}$ sodium acetate buffer ( $\mathrm{pH} 5$ ) containing $13.3 \mathrm{mM}$ p-nitrophenyl-D-glucuronide (Sigma-Aldrich) and 0.1\% Triton X-100. The reaction was terminated after $2 \mathrm{~h}$ by addition of $100 \mu \mathrm{L} 0.2 \mathrm{M}$ sodium hydroxide. Optical density was measured with a plate reader at $405 \mathrm{~nm}$. Both LDH- and GLU-based values were corrected for cell-free adsorption and normalized to the results of the positive control (0.1\% Triton X-100 in F-12K assay medium). 


\subsection{3. $\mathrm{TNF} \alpha$ Release}

The amount of released TNF $\alpha$ was determined using the rat TNF-alpha Quantikine ELISA Kit (Bio-Techne GmbH, Wiesbaden-Nordenstadt, Germany) as specified by the manufacturer. F-12K assay medium served as vehicle control. As positive control, the TNF $\alpha$-forming capacity of NR8383 cells was confirmed by stimulation with lipopolysaccharide $(0.1 \mu \mathrm{g} / \mathrm{mL}$; Sigma-Aldrich).

\subsubsection{Overall Evaluation of In Vitro Test Results to Distinguish between Passive and Active Test Materials}

The lowest concentration at which a significant effect (cf. Section 4.5) was recorded for a given parameter was termed in vitro LOAEC, and it was expressed in both nominal particle mass-based metrics $(\mu \mathrm{g} / \mathrm{mL})$ and nominal and calculated effective concentration particle surface area-based metrics $\left(\mathrm{mm}^{2} / \mathrm{mL}\right)$.

A test material concentration threshold of $<6000 \mathrm{~mm}^{2} / \mathrm{mL}$ was applied to rule out effects that were caused only under cellular overload conditions [22], i.e., to distinguish passive (MG3) from active (MG4) test materials according to the DF4nanoGrouping [32,33]. This threshold was estimated as corresponding to the highest particle surface area-based concentration that does not yet result in particle overload of the cultured NR8383 AMs, and was further calculated to correspond to the in vivo threshold value for lung cell overload conditions in the rat STIS [22].

To assign the test materials as either passive (MG3) or active (MG4), the in vitro LOAECs obtained for the four parameters (i.e., release of $\mathrm{H}_{2} \mathrm{O}_{2}, \mathrm{GLU}, \mathrm{LDH}$, or TNF $\alpha$ ) were compared to the threshold value of $6000 \mathrm{~mm}^{2} / \mathrm{mL}$. Any significant LOAEC recorded below this threshold value was interpreted as a biologically relevant, test material-specific cellular effect. Significant LOAECs that were recorded only at concentrations exceeding the threshold were interpreted as not test material-specific, but as being caused by the cellular overload. Test materials were assessed as active (MG4) if at least two of the four parameters yielded significant results under non-cellular-overload conditions (i.e., at concentrations below the threshold); they were assessed as passive (MG3) if they yielded 0 or 1 significant result at concentrations below this threshold [22].

\subsection{In Vivo Rat Intratracheal Instillation Study}

The in vivo rat intratracheal instillation study was performed in an Association for Assessment and Accreditation of Laboratory Animal Care-approved laboratory of the Experimental Toxicology and Ecology of BASF SE, Ludwigshafen, Germany, in accordance with the German Animal Welfare Act and the effective European Union Directive. Details on the in vivo rat intratracheal instillation study have been published by Maser et al. [59], who used lung and bone marrow cells from these animals for genotoxicity testing.

Bolus doses of $360 \mu \mathrm{g} 55 \mathrm{~nm}$ and $15 \mathrm{~nm} \mathrm{SiO} 2$ in $500 \mu \mathrm{L} 0.9 \% \mathrm{NaCl}$ (i.e., $720 \mu \mathrm{g} / \mathrm{mL}$ ) were administered to Wistar rats (Crl:WI; Charles River, Germany), 8 weeks old on the day of instillation, by single intratracheal instillation. For this purpose, 8 animals per test group and 8 control animals were deeply anesthetized by isoflurane and fixed in an appropriate application holder. Control animals were treated with $0.9 \% \mathrm{NaCl}$. Correct insertion of the cannula into the trachea was controlled by visual inspection to avoid insertion into the pharynx. Clinical observation of the animals was performed before and after the instillation procedure and once daily thereafter. The body weight of the animals was assessed before instillation, on the next day, and before gross necropsy. Three days after instillation, the animals were euthanized with Narcoren ${ }^{\circledR}(100 \mathrm{mg} / \mathrm{kg}$ body weight pentobarbital; Boehringer, Ingelheim, Germany), and 5 animals per test group were used to determine blood and BALF parameters, whereas 3 animals per test group were assigned for pathological and histopathological examination. All tissues with gross lesions and all organs associated with the respiratory tract (nasal cavity, larynx, trachea with bifurcation, lungs, and mediastinal lymph nodes) were embedded in paraffin, sectioned, and stained with hematoxylin-eosin for histopathological evaluation by light microscopy. 


\subsection{Statistical Analyis}

The significance of the in vitro data (NR8383 AM assay) was assessed for all 4 cellular parameters (release of $\mathrm{H}_{2} \mathrm{O}_{2}, \mathrm{LDH}, \mathrm{GLU}$, or TNF $\alpha$ ). Values were compared to the vehicle control data using Bonferroni multiple testing and Bonferroni correction. To analyze values from the in vivo rat intratracheal instillation study (clinical pathology data), 2-sided Mann-Whitney U test was used; $p$-values $\leq 0.05$ were considered significant.

\section{Conclusions}

Four colloidal amorphous $\mathrm{SiO}_{2}$ that differed only by PPS $(9 \mathrm{~nm} \mathrm{SiO}, 15 \mathrm{~nm} \mathrm{SiO}, 30 \mathrm{~nm} \mathrm{SiO}$, and $55 \mathrm{~nm} \mathrm{SiO} 2$ ) elicited concentration-dependent release of LDH, GLU, and TNF $\alpha\left(\right.$ and $\left.\mathrm{H}_{2} \mathrm{O}_{2}\right)$ in the in vitro NR8383 AM assay. Further, particle size and, hence, surface area dependency of the cellular effects of these nanomaterials was clearly recognizable. The NR8383 AM assay, the recommended in vitro test method to determine a nanomaterial's ability to induce cellular effects in Tier 2 of the DF4nanoGrouping [32,33], proved useful to assign the differently sized colloidal $\mathrm{SiO}_{2}$ as active (MG4) nanomaterials. Applying the two-out-of-four prediction model to evaluate the effective concentration-based test results, all four colloidal $\mathrm{SiO}_{2}$ were assigned as active (MG4). This assignment was also indicated by their dispersibility, a DF4nanoGrouping Tier 2 grouping criterion [32,33]. All four test materials remained well dispersed in protein-free media (with average agglomeration numbers below the DF4nanoGrouping threshold of 3 indicating activity (MG4)).

The in vitro test results are consistent with the findings from the intratracheal instillation study, where both $15 \mathrm{~nm}$ and $55 \mathrm{~nm} \mathrm{SiO} 2$ elicited pulmonary effects after administration of single bolus doses reflecting the $15 \mathrm{~nm} \mathrm{SiO}_{2}$ lung burden immediately after 5-day aerosol exposure in the rat STIS, as well as with available rat STIS data for $15 \mathrm{~nm} \mathrm{SiO}_{2}$ [15]. The particle size dependency of in vitro effects was confirmed in the intratracheal instillation study, where the smaller $15 \mathrm{~nm} \mathrm{SiO}{ }_{2}$ also induced more pronounced effects than the larger $55 \mathrm{~nm} \mathrm{SiO}_{2}$.

Previous work [22] highlighted the usefulness of the NR8383 AM assay in distinguishing passive (MG3) from active (MG4) nanomaterials. Therefore, this assay may become relevant for hazard and risk assessment of nanomaterials (Box 3). The present study further confirms the usefulness of the NR8383 $\mathrm{AM}$ assay to assess colloidal $\mathrm{SiO}_{2}$ while underlining the need to determine the effective concentration of such nanomaterials with limited gravitational settling. However, the NR8383 AM assay still has some uncertainties if the test materials do not readily come into contact with the cultured cells, as is the case for well-dispersed colloidal $\mathrm{SiO}_{2}$. For these test materials that poorly sedimented within the $16 \mathrm{~h}$ incubation period, calculating the effective concentration proved necessary for evaluation of the in vitro test results in spite of some uncertainties underlying these calculations. In the present study, the ISDD model [66] was applied to calculate the effective concentration. While this model assumes a probability of 1 that particles that come close to the cells adhere to them [66], the probability might be much lower for strongly negatively charged colloidal amorphous $\mathrm{SiO}_{2}$. Further research is merited to develop methodologies to quantitatively measure effective concentrations, taking into account sedimentation and diffusion of particles and their subsequent adhesion to the bottom of the culture wells or cultured cells. 
Box 3. Further hazard and risk assessment of nanomaterials assigned to one of the main groups (MG1-MG4) of the DF4nanoGrouping [32,33]).

MG1-soluble nanomaterials: The further hazard and risk assessment can rely on read-across to the dissolved materials [32,33]

MG2-biopersistent high aspect ratio nanomaterials: The further hazard and risk assessment should address their potential fibre toxicity [101-103].

MG3 - passive nanomaterials: For risk assessment, the general threshold limit value for dust is sufficient to ensure occupational safety upon long-term exposure since these nanomaterials do not elicit material-specific effects, but only cause effects under pulmonary overload conditions [104].

MG4-active nanomaterials: Merit in-depth investigations. For risk assessment, occupational exposure limits (lower than for dusts) should be established on a case-by-case basis [7].

Supplementary Materials: The following are available online at www.mdpi.com/2079-4991/8/3/160/s1: Figure S1: Sedimentation of colloidal amorphous $\mathrm{SiO}_{2}$ in Krebs-Ringer phosphate glucose (KRPG) buffer determined by analytical ultracentrifugation. Yellow: $9 \mathrm{~nm} \mathrm{SiO}$; gray: $15 \mathrm{~nm} \mathrm{SiO}{ }_{2}$; orange: $30 \mathrm{~nm} \mathrm{SiO}_{2}$; blue: $55 \mathrm{~nm} \mathrm{SiO}_{2}$. Figure S2A: Fraction of deposited dose calculated with the DG model [1] applying the "sticky bottom" assumption. Yellow: $55 \mathrm{~nm} \mathrm{SiO}_{2}$; gray: $30 \mathrm{~nm} \mathrm{SiO}_{2}$; orange: $15 \mathrm{~nm} \mathrm{SiO} 2$; blue: $9 \mathrm{~nm} \mathrm{SiO}_{2}$. Figure S2B: Fraction of deposited dose calculated with the DG model [1] applying the "reflective bottom" assumption. Yellow: $55 \mathrm{~nm} \mathrm{SiO}_{2}$; gray: $30 \mathrm{~nm} \mathrm{SiO}_{2}$; orange: $15 \mathrm{~nm} \mathrm{SiO}_{2}$; blue: $9 \mathrm{~nm} \mathrm{SiO} 2$. Table S1: Analytical ultracentrifugation (AUC) measurements of the proportion of applied test materials that reached the bottom of the vials by sedimentation. Table S2: In vitro NR8383 rat alveolar macrophage assay: Cellular endpoint-specific test results obtained for $55 \mathrm{~nm}$ $\mathrm{SiO}_{2}, 30 \mathrm{~nm} \mathrm{SiO} 2,15 \mathrm{~nm} \mathrm{SiO}$, and $9 \mathrm{~nm} \mathrm{SiO}$ (expressed as x-fold changes compared to corresponding medium control).

Acknowledgments: We thank Kai Werle for physicochemical characterization of the test materials. Parts of the study were funded by grants from the German Federal Ministry of Education and Research (BMBF, nanoCare, project number 03X0021C, and NanoGRAVUR, project number 03XP0002J).

Author Contributions: M.W., R.L., W.W., A.V. and S.B. conceived and designed the experiments; M.W., S.B., A.V., J.-G.K., W.W. and L.M.-H. Performed the experiments; M.W., R.L., J.-G.K., W.W., L.M.-H., A.V., S.B. and U.G.S. analyzed the data; U.G.S. wrote the paper. All authors commented on the manuscript and approved of its final version.

Conflicts of Interest: The authors declare no conflict of interest. M.W. and A.V. are employees of IBE R\&D gGmbH, a nonprofit institute. S.B., L.M.-H., J.-G.K., W.W. and R.L. are employees of BASF SE, a chemical company producing and marketing nanomaterials (but not the test materials of the present study, which were selected based on purely scientific considerations). U.G.S. was contracted by BASF SE. The relevant business units of BASF $\mathrm{SE}$ had no role in the design of the study; in the collection, analysis, or interpretation of data; in the decision to publish the results; or in the writing of the manuscript.

\section{References}

1. Nel, A.E.; Nasser, E.; Godwin, H.; Avery, D.; Bahadori, T.; Bergeson, L.; Beryt, E.; Bonner, J.C.; Boverhof, D.; Carter, J.; et al. A multi-stakeholder perspective on the use of alternative test strategies for nanomaterial safety assessment. ACS Nano 2013, 7, 6422-6433. [CrossRef] [PubMed]

2. Stark, W.J.; Stoessel, P.R.; Wohlleben, W.; Hafner, A. Industrial applications of nanoparticles. Chem. Soc. Rev. 2015, 44, 5793-5805. [CrossRef] [PubMed]

3. Fruijtier-Pölloth, C. The toxicological mode of action and the safety of synthetic amorphous silica-A nanostructured material. Toxicology 2012, 294, 61-67. [CrossRef] [PubMed]

4. $\quad$ Arts, J.H.; Hadi, M.; Keene, A.M.; Kreiling, R.; Lyon, D.; Maier, M.; Michel, K.; Petry, T.; Sauer, U.G.; Warheit, D.; et al. A critical appraisal of existing concepts for the grouping of nanomaterials. Regul. Toxicol. Pharmacol. 2014, 70, 492-506. [CrossRef] [PubMed]

5. Landsiedel, R.; Wiench, K.; Wohlleben, W. Geeignete Methoden zur Prüfung der Sicherheit von Nanomaterialien. Chem. Ing. Tech. 2008, 80, 1641-1651. [CrossRef]

6. Landsiedel, R.; Sauer, U.G.; Ma-Hock, L.; Schnekenburger, J.; Wiemann, M. Pulmonary toxicity of nanomaterials: A critical comparison of published in vitro assays with in vivo inhalation or instillation studies. Nanomedicine 2014, 9, 2557-2585. [CrossRef] [PubMed]

7. Landsiedel, R.; Ma-Hock, L.; Wiench, K.; Wohlleben, W.; Sauer, U.G. Safety assessment of nanomaterials using an advanced decision-making framework, the DF4nanoGrouping. J. Nanopart. Res. 2017, 19, 171. [CrossRef] [PubMed] 
8. Regulation (EC) No 1907/2006 of the European Parliament and of the Council of 18 December 2006 Concerning the Registration, Evaluation, Authorisation and Restriction of Chemicals (REACH), Establishing a European Chemicals Agency, Amending Directive 1999/45/EC and Repealing Council Regulation (EEC) No 793/93 and Commission Regulation (EC) No 1488/94 as well as Council Directive 76/769/EEC and Commission Directives 91/155/EEC, 93/67/EEC, 93/105/EC and 2000/21/EC. OJ L 396/1. 30 December 2003. Available online: http:/ / data.europa.eu/eli/reg/2006/1907/2014-04-10 (accessed on 1 February 2018).

9. Burden, N.; Aschberger, K.; Chaudhry, Q.; Clift, M.J.; Doak, S.H.; Fowler, P.; Johnston, J.H.; Landsiedel, R.; Rowland, J.; Stone, V. The 3Rs as a framework to support a 21st century approach for nanosafety assessment. Nano Today 2017, 12, 10-13. [CrossRef]

10. Russell, W.M.S.; Burch, R.L. The Principles of Humane Experimental Technique; Methuen: London, UK, 1959; p. 238.

11. Directive 2010/63/EU of the European Parliament and of the Council of 22 September 2010 on the Protection of Animals Used for Scientific Purposes. OJ L 276/33. 20 October 2010. Available online: http:/ / data.europa. eu/eli/dir/2010/63/oj (accessed on 1 February 2018).

12. Klein, C.L.; Wiench, K.; Wiemann, M.; Ma-Hock, L.; van Ravenzwaay, B.; Landsiedel, R. Hazard identification of inhaled nanomaterials: Making use of short-term inhalation studies. Arch. Toxicol. 2012, 86, 1137-1151. [CrossRef] [PubMed]

13. Arts, J.H.; Muijser, H.; Duistermaat, E.; Junker, K.; Kuper, C.F. Five-day inhalation toxicity study of three types of synthetic amorphous silicas in Wistar rats and post-exposure evaluations for up to 3 months. Food Chem. Toxicol. 2007, 45, 1856-1867. [CrossRef] [PubMed]

14. Ma-Hock, L.; Burkhardt, S.; Strauss, V.; Gamer, A.O.; Wiench, K.; van Ravenzwaay, B.; Landsiedel, R. Development of a short-term inhalation test in the rat using nano-titanium dioxide as a model substance. Inhal. Toxicol. 2009, 21, 102-118. [CrossRef] [PubMed]

15. Landsiedel, R.; Ma-Hock, L.; Hofmann, T.; Wiemann, M.; Strauss, V.; Treumann, S.; Wohlleben, W.; Gröters, S.; Wiench, K.; van Ravenzwaay, B. Application of short-term inhalation studies to assess the inhalation toxicity of nanomaterials. Part. Fibre Toxicol. 2014, 11, 16. [CrossRef] [PubMed]

16. Kroll, A.; Dierker, C.; Rommel, C.; Hahn, D.; Wohlleben, W.; Schulze-Isfort, C.; Göbbert, C.; Voetz, M.; Hardinghaus, F.; Schnekenburger, J. Cytotoxicity screening of 23 engineered nanomaterials using a test matrix of ten cell lines and three different assays. Part. Fibre Toxicol. 2011, 8, 9. [CrossRef] [PubMed]

17. Xia, T.; Hamilton, R.F.; Bonner, J.C.; Crandall, E.D.; Elder, A.; Fazlollahi, F.; Girtsman, T.A.; Kim, K.; Mitra, S.; Ntim, S.A.; et al. Interlaboratory evaluation of in vitro cytotoxicity and inflammatory responses to engineered nanomaterials: The NIEHS Nano GO Consortium. Environ. Health Perspect. 2013, 121, 683-690. [CrossRef] [PubMed]

18. Guadagnini, R.; Halamoda Kenzaoui, B.; Walker, L.; Pojana, G.; Magdolenova, Z.; Bilanicova, D.; Saunders, M.; Juillerat-Jeanneret, L.; Marcomini, A.; Huk, A.; et al. Toxicity screenings of nanomaterials: Challenges due to interference with assay processes and components of classic in vitro tests. Nanotoxicology 2015, 9 (Suppl. 1), 13-24. [CrossRef] [PubMed]

19. Rushton, E.K.; Jiang, J.; Leonard, S.S.; Eberly, S.; Castranova, V.; Biswas, P.; Elder, A.; Han, X.; Gelein, R.; Finkelstein, J.; et al. Concept of assessing nanoparticle hazards considering nanoparticle dosemetric and chemical/biological response metrics. J. Toxicol. Environ. Health A 2010, 73, 445-461. [CrossRef] [PubMed]

20. Cho, W.S.; Duffin, R.; Bradley, M.; Megson, I.L.; MacNee, W.; Lee, J.K.; Jeong, J.; Donaldson, K. Predictive value of in vitro assays depends on the mechanism of toxicity of metal oxide nanoparticles. Part. Fibre Toxicol. 2013, 10, 55. [CrossRef] [PubMed]

21. Han, X.; Corson, N.; Wade-Mercer, P.; Gelein, R.; Jiang, J.; Sahu, M.; Biswas, P.; Finkelstein, J.N.; Elder, A.; Oberdörster, G. Assessing the relevance of in vitro studies in nanotoxicology by examining correlations between in vitro and in vivo data. Toxicology 2012, 297, 1-9. [CrossRef] [PubMed]

22. Wiemann, M.; Vennemann, A.; Sauer, U.G.; Wiench, K.; Ma-Hock, L.; Landsiedel, R. An alveolar macrophage assay for predicting the short-term inhalation toxicity of nanomaterials. J. Nanobiotechnol. 2016, 14, 16. [CrossRef] [PubMed]

23. Fels, A.O.S.; Cohn, Z.A. The alveolar macrophage. J. Appl. Physiol. 1986, 60, 353-369. [CrossRef] [PubMed]

24. Driscoll, K.E.; Higgins, J.M.; Leytart, M.J.; Crosby, L.L. Differential effects of mineral dusts on the in vitro activation of alveolar macrophage eicosanoid and cytokine release. Toxicol. In Vitro 1990, 4, 284-288. [CrossRef] 
25. Rehn, B.; Bruch, J.; Tong, Z.; Hobusch, G. Recovery of rat alveolar macrophages by bronchoalveolar lavage under normal and activated conditions. Environ. Health. Perspect. 1992, 97, 11-16. [CrossRef] [PubMed]

26. Rehn, B.; Rehn, S.; Bruch, J. Ein neues In Vitro-Prüfkonzept (Vektormodell) zum biologischen Screening und Monitoring der Lungentoxizität von Stäuben. Gefahrst. Reinhalt. Luft 1999, 59, 181-188.

27. Bruch, J.; Rehn, S.; Rehn, B.; Borm, P.J.; Fubini, B. Variation of biological responses to different respirable quartz flours determined by a vector model. Int. J. Hyg. Environ. Health 2004, 207, 203-216. [CrossRef] [PubMed]

28. Bruch, J.; Rehn, B.; Duval-Arnould, G.; Efskind, J.; Röderer, G.; Sébastian, P. Toxicological investigations on the respirable fraction of silicon carbide grain products by the in vitro vector model. Inhal. Toxicol. 2014, 26, 278-288. [CrossRef] [PubMed]

29. Helmke, R.J.; Boyd, R.L.; German, V.F.; Mangos, J.A. From growth factor dependence to growth factor responsiveness: The genesis of an alveolar macrophage cell line. In Vitro Cell. Dev. Biol. 1987, 23, 567-574. [CrossRef] [PubMed]

30. Helmke, R.J.; German, V.F.; Mangos, J.A. A continuous alveolar macrophage cell line: Comparisons with freshly derived alveolar macrophages. In Vitro Cell. Dev. Biol. 1989, 25, 44-48. [CrossRef] [PubMed]

31. Schremmer, I.; Brik, A.; Weber, D.G.; Rosenkranz, N.; Rostek, A.; Loza, K.; Brüning, T.; Johnen, G.; Epple, M.; Bünger, J.; et al. Kinetics of chemotaxis, cytokine, and chemokine release of NR8383 macrophages after exposure to inflammatory and inert granular insoluble particles. Toxicol. Lett. 2016, 263, 68-75. [CrossRef] [PubMed]

32. Arts, J.H.; Hadi, M.; Irfan, M.A.; Keene, A.M.; Kreiling, R.; Lyon, D.; Maier, M.; Michel, K.; Petry, T.; Sauer, U.G.; et al. A decision-making framework for the grouping and testing of nanomaterials (DF4nanoGrouping). Regul. Toxicol. Pharmacol. 2015, 71, S1-S7. [CrossRef] [PubMed]

33. Arts, J.; Irfan, M.A.; Keene, A.M.; Kreiling, R.; Lyon, D.; Maier, M.; Michel, K.; Neubauer, N.; Petry, T.; Sauer, U.G.; et al. Case studies putting the decision-making framework for the grouping and testing of nanomaterials (DF4nanoGrouping) into practice. Regul. Toxicol. Pharmacol. 2016, 76, 234-261. [CrossRef] [PubMed]

34. Gebel, T.; Foth, H.; Damm, G.; Feyberger, A.; Kramer, P.J.; Lilienblum, W.; Röhl, C.; Schupp, T.; Weiss, C.; Wollin, K.M.; et al. Manufactured nanomaterials: Categorization and approaches to hazard assessment. Arch. Toxicol. 2014, 88, 2191-2211. [CrossRef] [PubMed]

35. Godwin, H.; Nameth, C.; Avery, D.; Bergeson, L.L.; Bernard, D.; Beryt, E.; Boyes, W.; Brown, S.; Clippinger, A.J.; Cohen, Y.; et al. Nanomaterial categorization for assessing risk potential to facilitate regulatory decision-making. ACS Nano 2015, 9, 3409-3417. [CrossRef] [PubMed]

36. Nel, A.E.; Parak, W.J.; Chan, W.C.; Xia, T.; Hersam, M.C.; Brinker, C.J.; Zink, J.I.; Pinkerton, K.E.; Baer, D.R.; Weiss, P.S. Where are we heading in nanotechnology environmental health and safety and materials characterization? ACS Nano 2015, 9, 5627-5630. [CrossRef] [PubMed]

37. Oomen, A.G.; Bos, P.M.J.; Fernandes, T.F.; Hund-Rinke, K.; Boraschi, D.; Byrne, H.J.; Aschberger, K.; Gottardo, S.; van der Kammer, F.; Kühnel, D.; et al. Concern-driven integrated approaches to nanomaterial testing and assessment-Report of the NanoSafety Cluster Working Group 10. Nanotoxicology 2014, 8, 334-348. [CrossRef] [PubMed]

38. Oomen, A.G.; Steinhäuser, K.G.; Bleeker, E.A.J.; van Broekhuizen, F.; Sips, A.; Dekkers, S.; Wijnhoven, S.W.P.; Sayre, P.G. Risk assessment frameworks for nanomaterials: Scope, link to regulations, applicability, and outline for future directions in view of needed increase in efficiency. Nanolmpact 2017. [CrossRef]

39. Go, M.R.; Bae, S.H.; Kim, H.J.; Yu, J.; Choi, S.J. Interactions between food additive silica nanoparticles and food matrices. Front. Microbiol. 2017, 8, 1013. [CrossRef] [PubMed]

40. Murugadoss, S.; Lison, D.; Godderis, L.; Van Den Brule, S.; Mast, J.; Brassinne, F.; Sebaihi, N.; Hoet, P.H. Toxicology of silica nanoparticles: An update. Arch. Toxicol. 2017. [CrossRef] [PubMed]

41. Wohlleben, W. Validity range of centrifuges for the regulation of nanomaterials: From classification to as-tested coronas. J. Nanopart. Res. 2012, 14, 1300. [CrossRef] [PubMed]

42. Razzaboni, B.L.; Bolsaitis, P. Evidence of an oxidative mechanism for the haemolytic activity of silica particles. Environ. Health Perspect. 1990, 87, 337-341. [CrossRef] [PubMed]

43. Oberdörster, G.; Ferin, J.; Lehnert, B.E. Correlation between particle size, in vivo particle persistence, and lung injury. Environ. Health Perspect. 1994, 102, 173-179. [CrossRef] [PubMed] 
44. Oberdörster, G.; Oberdörster, E.; Oberdörster, J. Nanotoxicology: An emerging discipline evolving from studies of ultrafine particles. Environ. Health Perspect. 2005, 113, 823-839. [CrossRef] [PubMed]

45. Oberdörster, G. Safety assessment for nanotechnology and nanomedicine: Concepts of nanotoxicology. J. Int. Med. 2009, 267, 89-105. [CrossRef] [PubMed]

46. Roser, M.; Fischer, D.; Kissel, T. Surface-modified biodegradable albumin nano- and microspheres. II: Effect of surface charges on in vitro phagocytosis and biodistribution in rats. Eur. J. Pharm. Biopharm. 1998, 46, 255-263. [CrossRef]

47. Kreyling, W.G.; Semmler, M.; Erbe, F.; Mayer, P.; Takenaka, S.; Schulz, H.; Oberdörster, G.; Ziesenis, A. Translocation of ultrafine insoluble iridium particles from lung epithelium to extrapulmonary organs is size dependent but very low. J. Toxicol. Environ. Health Part A 2002, 65, 1513-1530. [CrossRef] [PubMed]

48. Kreyling, W.G.; Semmler-Behnke, M.; Seitz, J.; Scymczak, W.; Wenk, A.; Mayer, P.; Takenaka, S.; Oberdörster, G. Size dependence of the translocation of inhaled iridium and carbon nanoparticle aggregates from the lung of rats to the blood and secondary target organs. Inhal. Toxicol. 2009, 21, 55-60. [CrossRef] [PubMed]

49. Warheit, D.B.; Webb, T.R.; Sayes, C.M.; Colvin, V.L.; Reed, K.L. Pulmonary instillation studies with nanoscale $\mathrm{TiO}_{2}$ rods and dots in rats: Toxicity is not dependent upon particle size and surface area. Toxicol. Sci. 2006, 91, 227-236. [CrossRef] [PubMed]

50. Warheit, D.B.; Webb, T.R.; Colvin, V.L.; Reed, K.L.; Sayes, C.R. Pulmonary bioassay studies with nanoscale and fine-quartz particles in rats: Toxicity is not dependent upon particle size but on surface characteristics. Toxicol. Sci. 2007, 95, 270-280. [CrossRef] [PubMed]

51. Decan, N.; Wu, D.; Williams, A.; Bernatchez, S.; Johnston, M.; Hill, M.; Halappanavar, S. Characterization of in vitro genotoxic, cytotoxic and transcriptomic responses following exposures to amorphous silica of different sizes. Mutat. Res. 2016, 796, 8-22. [CrossRef] [PubMed]

52. Commission. Recommendation on the Definition of Nanomaterial. OJ L 275, 38 . 18 October 2011. Available online: https:/ / ec.europa.eu/research/industrial_technologies/pdf/policy/commissionrecommendation-on-the-definition-of-nanomater-18102011_en.pdf (accessed on 1 February 2018).

53. Boverhof, D.R.; Bramante, C.M.; Butala, J.H.; Clancy, S.F.; Lafranconi, M.; West, J.; Gordon, S.C. Comparative assessment of nanomaterial definitions and safety evaluation considerations. Regul. Toxicol. Pharmacol. 2015, 73, 137-150. [CrossRef] [PubMed]

54. Donaldson, K.; Poland, C.A. Nanotoxicity: Challenging the myth of nano-specific toxicity. Curr. Opin. Biotechnol. 2013, 24, 724-734. [CrossRef] [PubMed]

55. Wohlleben, W.; Driessen, M.D.; Raesch, S.; Schaefer, U.F.; Schulze, C.; von Vacano, B.; Vennemann, A.; Wiemann, M.; Ruge, C.A.; Platsch, H.; et al. Influence of agglomeration and specific lung lining lipid/protein interaction on short-term inhalation toxicity. Nanotoxicology 2016, 10, 970-980. [CrossRef] [PubMed]

56. Teeguarden, J.G.; Hinderliter, P.M.; Orr, G.; Thrall, B.D.; Pounds, J.G. Particokinetics in vitro: Dosimetry considerations for in vitro nanoparticle toxicity assessments. Toxicol. Sci. 2007, 95, 300-312. [CrossRef] [PubMed]

57. Cohen, J.M.; Teeguarden, J.G.; Demokritou, P. An integrated approach for the in vitro dosimetry of engineered nanomaterials. Part. Fibre Toxicol. 2014, 11, 20. [CrossRef] [PubMed]

58. Cohen, J.M.; DeLoid, G.M.; Demokritou, P. A critical review of in vitro dosimetry for engineered nanomaterials. Nanomedicine 2015, 10, 3015-3032. [CrossRef] [PubMed]

59. Maser, E.; Schulz, M.; Sauer, U.G.; Wiemann, M.; Ma-Hock, L.; Wohlleben, W.; Hartwig, A.; Landsiedel, R. In vitro and in vivo genotoxicity investigations of differently sized amorphous $\mathrm{SiO}_{2}$ nanomaterials. Mut. Res. 2015, 794, 57-74. [CrossRef] [PubMed]

60. Organisation for Economic Co-operation and Development. Test Guideline for the Testing of Dissolution Rate of Nanomaterials in Aquatic Media; OECD: Paris, France, 2017.

61. Gorrepati, E.A.; Wongthahan, P.; Raha, S.; Fogler, H.S. Silica precipitation in acidic solutions: Mechanism, pH effect, and salt effect. Langmuir 2010, 26, 10467-10474. [CrossRef] [PubMed]

62. Gandon, A.; Werle, K.; Neubauer, N.; Wohlleben, W. Surface reactivity measurements as required for grouping and read-across: An advanced FRAS protocol. J. Phys. Conf. Ser. 2017, 838, 012033. [CrossRef]

63. Schaefer, J.; Schulze, C.; Marxer, E.E.; Schaefer, U.F.; Wohlleben, W.; Bakowsky, U.; Lehr, C.-M. Atomic force microscopy and analytical ultracentrifugation for probing nanomaterial protein interactions. ACS Nano 2012, 6, 4603-4614. [CrossRef] [PubMed] 
64. Izak-Nau, E.; Voetz, M. As-produced: Intrinsic physico-chemical properties and appropriate characterization tools. In Safety of Nanomaterials along Their Lifecycle: Release, Exposure, and Human Hazards; Wohlleben, W., Kuhlbusch, T., Lehr, C.-M., Schnekenburger, J., Eds.; CRC Press: Boca Raton, FL, USA, 2014; pp. 3-23.

65. Chen, R.; Zhang, Y.; Darabi Sahneh, F.; Scoglio, C.M.; Wohlleben, W.; Haase, A.; Monteiro-Riviere, N.A.; Riviere, J.E. Nanoparticle surface characterization and clustering through concentration-dependent surface adsorption modeling. ACS Nano 2014, 8, 9446-9456. [CrossRef] [PubMed]

66. Hinderliter, P.M.; Minard, K.R.; Orr, G.; Chrisler, W.B.; Thrall, B.D.; Pounds, J.G.; Teeguarden, J.G. ISDD: A computational model of particle sedimentation, diffusion and target cell dosimetry for in vitro toxicity studies. Part. Fibre Toxicol. 2010, 7, 36. [CrossRef] [PubMed]

67. DeLoid, G.M.; Cohen, J.M.; Pyrgiotakis, G.; Pirela, S.V.; Pal, A.; Liu, J.; Srebric, J.; Demokritou, P. Advanced computational modeling for in vitro nanomaterial dosimetry. Part. Fibre Toxicol. 2015, 12, 32. [CrossRef] [PubMed]

68. DeLoid, G.M.; Cohen, J.M.; Pyrgiotakis, G.; Demokritou, P. Preparation, characterization, and in vitro dosimetry of dispersed, engineered nanomaterials. Nat. Protoc. 2017, 12, 355-371. [CrossRef] [PubMed]

69. Peuschel, H.; Ruckelshausen, T.; Cavelius, C.; Kraegeloh, A. Quantification of Internalized Silica Nanoparticles via STED Microscopy. Biomed. Res. Int. 2015, 2015, 961208. [CrossRef] [PubMed]

70. Leontaridou, M.; Urbisch, D.; Kolle, S.N.; Ott, K.; Mulliner, D.S.; Gabbert, S.; Landsiedel, R. Quantification of the borderline range and implications for evaluating non-animal testing methods' precision. ALTEX 2017, 34, 525-538. [CrossRef] [PubMed]

71. Baron, L.; Gombault, A.; Fanny, M.; Villeret, B.; Savigny, F.; Guillou, N.; Panek, C.; Le Bert, M.; Lagente, V.; Rassendren, F; et al. The NLRP3 inflammasome is activated by nanoparticles through ATP, ADP and adenosine. Cell Death Dis. 2015, 6, e1629. [CrossRef] [PubMed]

72. Desch, C.E.; Dobrina, A.; Aggarwal, B.B.; Harlan, J.M. Tumor necrosis factor-alpha exhibits greater proinflammatory activity than lymphotoxin in vitro. Blood 1990, 75, 2030-2034. [PubMed]

73. Duffin, R.; Tran, L.; Brown, D.; Stone, V.; Donaldson, K. Proinflammogenic effects of low-toxicity and metal nanoparticles in vivo and in vitro: Highlighting the role of particle surface area and surface reactivity. Inhal. Toxicol. 2007, 19, 849-856. [CrossRef] [PubMed]

74. Nel, A.E.; Mädler, L.; Velegol, D.; Xia, T.; Hoek, E.M.V.; Somasundaran, P.; Klaessig, F.; Castranova, V.; Thompson, M. Understanding biophysicochemical interactions at the nano-bio interface. Nat. Mater. 2009, 8, 543-557. [CrossRef] [PubMed]

75. Tran, C.L.; Buchanan, D.; Cullen, R.T.; Searl, A.; Jones, A.D.; Donaldson, K. Inhalation of poorly soluble particles. II. Influence of particle surface area on inflammation and clearance. Inhal. Toxicol. 2000, 12, 1113-1126. [PubMed]

76. Halamoda-Kenzaoui, B.; Ceridono, M.; Colpo, P.; Valsesia, A.; Urbán, P.; Ojea-Jiménez, I.; Gioria, S.; Gilliland, D.; Rossi, F.; Kinsner-Ovaskainen, A. Dispersion behaviour of silica nanoparticles in biological media and its influence on cellular uptake. PLOS ONE 2015, 10, e0141593. [CrossRef] [PubMed]

77. Halamoda-Kenzaoui, B.; Ceridono, M.; Urbán, P.; Bogni, A.; Ponti, J.; Gioria, S.; Kinsner-Ovaskainen, A. The agglomeration state of nanoparticles can influence the mechanism of their cellular internalisation. J. Nanobiotechnol. 2017, 15, 48. [CrossRef] [PubMed]

78. Sauer, U.G.; Aumann, A.; Ma-Hock, L.; Landsiedel, R.; Wohlleben, W. Influence of dispersive agent on nanomaterial agglomeration and implications for biological effects in vivo or in vitro. Toxicol. In Vitro 2015, 29, 182-186. [CrossRef] [PubMed]

79. Yadav, I.; Aswal, V.K.; Kohlbrecher, J. Size-dependent interaction of silica nanoparticles with lysozyme and bovine serum albumin proteins. Phys. Rev. E 2016, 93, 052601. [CrossRef] [PubMed]

80. Lison, D.; Thomassen, L.C.; Rabolli, V.; Gonzalez, L.; Napierska, D.; Seo, J.W.; Kirsch-Volders, M.; Hoet, P.; Kirschhock, C.E.; Martens, J.A. Nominal and effective dosimetry of silica nanoparticles in cytotoxicity assays. Toxicol. Sci. 2008, 104, 155-162. [CrossRef] [PubMed]

81. Vicente, S.; Moia, C.; Zhu, H.; Vigé, X. In vitro evaluation of the internalization and toxicological profile of silica nanoparticles and submicroparticles for the design of dermal drug delivery strategies. J. Appl. Toxicol. 2017. [CrossRef] [PubMed]

82. Fröhlich, E. The role of surface charge in cellular uptake and cytotoxicity of medical nanoparticles. Int. J. Nanomed. 2012, 7, 5577-5591. [CrossRef] [PubMed] 
83. Shi, J.; Karlsson, H.L.; Johansson, K.; Gogvadze, V.; Xiao, L.; Li, J.; Burks, T.; Garcia-Bennett, A.E.; Uheida, A.; Muhammed, M.; et al. Microsomal glutathione transferase 1 protects against toxicity induced by silica nanoparticles but not by zinc oxide nanoparticles. ACS Nano 2012, 6, 1925-1938. [CrossRef] [PubMed]

84. Coccini, T.; Manzo, L.; Roda, E. Safety evaluation of engineered nanomaterials for health risk assessment: An experimental tiered testing approach using pristine and functionalized carbon nanotubes. ISRN Toxicol. 2013, 2013, 825427. [CrossRef] [PubMed]

85. Panas, A.; Marquardt, C.; Nalcaci, O.; Bockhorn, H.; Baumann, W.; Paur, H.R.; Mülhopt, S.; Diabaté, S.; Weiss, C. Screening of different metal oxide nanoparticles reveals selective toxicity and inflammatory potential of silica nanoparticles in lung epithelial cells and macrophages. Nanotoxicology 2013, 7, 259-273. [CrossRef] [PubMed]

86. Saikia, J.; Yazdimamaghani, M.; Hadipour Moghaddam, S.P.; Ghandehari, H. Differential protein adsorption and cellular uptake of silica nanoparticles based on size and porosity. ACS Appl. Mater. Interfaces 2016, 8, 34820-34832. [CrossRef] [PubMed]

87. Haase, A.; Dommershausen, N.; Schulz, M.; Landsiedel, R.; Reichardt, P.; Krause, B.C.; Tentschert, J.; Luch, A. Genotoxicity testing of different surface-functionalized $\mathrm{SiO}_{2}, \mathrm{ZrO}_{2}$ and silver nanomaterials in 3D human bronchial models. Arch. Toxicol. 2017, 91, 3991-4007. [CrossRef] [PubMed]

88. Wills, J.W.; Hondow, N.; Thomas, A.D.; Chapman, K.E.; Fish, D.; Maffeis, T.G.; Penny, M.W.; Brown, R.A.; Jenkins, G.J.; Brown, A.P.; et al. Genetic toxicity assessment of engineered nanoparticles using a 3D in vitro skin model (EpiDerm ${ }^{\mathrm{TM}}$ ). Part. Fibre Toxicol. 2016, 13, 50. [CrossRef] [PubMed]

89. Keller, J.; Wohlleben, W.; Ma-Hock, L.; Groeters, S.; Küttler, K.; Strauss, V.; Wiench, K.E.; Herden, C.; Oberdörster, G.; van Ravenzwaay, B.; et al. Time-course of lung retention and toxicity of inhaled particles: Short-term exposure to nano-Ceria. Arch. Toxicol. 2014, 88, 2033-2059. [CrossRef] [PubMed]

90. Hussell, T.; Bell, T.J. Alveolar macrophages: Plasticity in a tissue-specific context. Nat. Rev. Immunol. 2014, 14, 81-93. [CrossRef] [PubMed]

91. Wohlleben, W.; Kolle, S.N.; Hasenkamp, L.C.; Böser, A.; Vogel, S.; von Vacano, B.; van Ravenzwaay, B.; Landsiedel, R. Artifacts by marker enzyme adsorption on nanomaterials in cytotoxicity assays with tissue cultures. J. Phys. Conf. Ser. 2011, 304, 012061. [CrossRef]

92. Buesen, R.; Landsiedel, R.; Sauer, U.G.; Wohlleben, W.; Strauss, V.; Groeters, S.; Kamp, H.G.; van Ravenzwaay, B. Effects of $\mathrm{SiO}_{2}, \mathrm{ZrO}_{2}$, and $\mathrm{BaSO}_{4}$ nanomaterials with or without surface functionalization upon 28-day oral exposure to rats. Arch. Toxicol. 2014, 88, 1881-1906. [CrossRef] [PubMed]

93. Hofmann, T.; Schneider, S.; Wolterbeek, A.; van de Sandt, H.; Landsiedel, R.; van Ravenzwaay, B. Prenatal toxicity of synthetic amorphous silica nanomaterial in rats. Reprod. Toxicol. 2015, 56, 141-146. [CrossRef] [PubMed]

94. Wolterbeek, A.; Oosterwijk, T.; Schneider, S.; Landsiedel, R.; de Groot, D.; van Ee, R.; Wouters, M.; van de Sandt, H. Oral two-generation reproduction toxicity study with NM-200 synthetic amorphous silica in Wistar rats. Reprod. Toxicol. 2015, 56, 147-154. [CrossRef] [PubMed]

95. Kolle, S.N.; Sauer, U.G.; Moreno, M.C.R.; Teubner, W.; Wohlleben, W.; Landsiedel, R. Eye irritation testing of nanomaterials using the EpiOcular ${ }^{\mathrm{TM}}$ eye irritation test and the bovine corneal opacity and permeability assay. Part. Fibre Toxicol. 2016, 13, 18. [CrossRef] [PubMed]

96. Wohlleben, W.; Ma-Hock, L.; Boyko, V.; Cox, G.; Egenolf, H.; Freiberger, H.; Hinrichsen, B.; Hirth, S.; Landsiedel, R. Nanospecific guidance in REACH: A comparative physicalchemical characterization of 15 materials with methodical correlations. J. Ceram. Sci. Technol. 2013, 4, 93-104.

97. Avramescu, M.L.; Rasmussen, P.E.; Chénier, M.; Gardner, H.D. Influence of pH, particle size and crystal form on dissolution behaviour of engineered nanomaterials. Environ. Sci. Pollut. Res. Int. 2017, 24, 1553-1564. [CrossRef] [PubMed]

98. Wohlleben, W.; Waindok, H.; Daumann, B.; Werle, K.; Drum, M.; Egenolf, H. Composition, respirable fraction and dissolution rate of 24 stone wool MMVF with their binder. Part. Fibre Toxicol. 2017, 14, 29. [CrossRef] [PubMed]

99. Dethloff, L.A.; Gladen, B.C.; Gilmore, L.B.; Hook, G.E.R. Quantitation of cellular and extracellular constituents of the pulmonary lining in rats by using bronchoalveolar lavage-Effects of silica-induced pulmonary inflammation. Am. Rev. Respir. Dis. 1987, 136, 899-907. [CrossRef] [PubMed]

100. Lehnert, B.E.; Valdez, Y.E.; Holland, L.M. Pulmonary macrophages: Alveolar and interstitial populations. Exp. Lung Res. 1985, 9, 177-190. [CrossRef] [PubMed] 
101. Donaldson, K.; Murphy, F.A.; Duffin, R.; Poland, C.A. Asbestos, carbon nanotubes and the pleural mesothelium: A review of the hypothesis regarding the role of long fibre retention in the parietal pleura, inflammation and mesothelioma. Part. Fibre Toxicol. 2010, 7, 5. [CrossRef] [PubMed]

102. Donaldson, K.; Murphy, F.; Schinwald, A.; Duffin, R.; Poland, C.A. Identifying the pulmonary hazard of high aspect ratio nanoparticles to enable their safety-by-design. Nanomedicine 2011, 6, 143-156. [CrossRef] [PubMed]

103. Poland, C.A.; Duffin, R.; Donaldson, K. High aspect nanoparticles and the fibre pathogenicity paradigm. In Nanotoxicity: From In Vivo and In Vitro Models to Health Risks; Sahu, S.C., Casciano, D.A., Eds.; Wiley-VCH Verlag GmbH: Weinheim, Germany, 2009; Chapter 4; ISBN 978-0-47-074137-5.

104. ECETOC. European Centre for Ecotoxicology and Toxicology of Chemicals Technical Report 122; Poorly Soluble Particles; Lung Overload; ECETOC: Brussels, Belgium, 2013.

(C) 2018 by the authors. Licensee MDPI, Basel, Switzerland. This article is an open access article distributed under the terms and conditions of the Creative Commons Attribution (CC BY) license (http:/ / creativecommons.org/licenses/by/4.0/). 